\title{
Chemical discrimination of the particulate and gas phases of miniCAST exhausts using a two-filter collection method
}

\author{
Linh Dan Ngo ${ }^{1,2}$, Dumitru Duca ${ }^{1}$, Yvain Carpentier ${ }^{1}$, Jennifer A. Noble ${ }^{1, a}$, Raouf Ikhenazene ${ }^{1}$, Marin Vojkovic ${ }^{1}$, \\ Cornelia Irimiea $^{3}$, Ismael K. Ortega ${ }^{3}$, Guillaume Lefevre ${ }^{4}$, Jérôme Yon $^{4}$, Alessandro Faccinetto ${ }^{2}$, Eric Therssen ${ }^{2}$, \\ Michael Ziskind $^{2}$, Bertrand Chazallon ${ }^{2}$, Claire Pirim ${ }^{1}$, and Cristian Focsa ${ }^{1}$ \\ ${ }^{1}$ Univ. Lille, CNRS, UMR 8523 - PhLAM - Laboratoire de Physique des Lasers Atomes et Molécules, 59000 Lille, France \\ ${ }^{2}$ Univ. Lille, CNRS, UMR 8522 - PC2A - Physicochimie des Processus de Combustion et de l'Atmosphère, \\ 59000 Lille, France \\ ${ }^{3}$ ONERA - The French Aerospace Laboratory, 91123 Palaiseau, France \\ ${ }^{4}$ Normandie Univ., INSA Rouen, UNIROUEN, CNRS, CORIA, 76000 Rouen, France \\ ${ }^{a}$ now at: CNRS, Aix Marseille Université, PIIM, UMR 7345, 13397 Marseille CEDEX, France
}

Correspondence: Yvain Carpentier (yvain.carpentier@univ-lille.fr)

Received: 13 July 2019 - Discussion started: 5 September 2019

Revised: 4 January 2020 - Accepted: 18 January 2020 - Published: 28 February 2020

\begin{abstract}
Combustion of hydrocarbons produces both particulate- and gas-phase emissions responsible for major impacts on atmospheric chemistry and human health. Ascertaining the impact of these emissions, especially on human health, is not straightforward because of our relatively poor knowledge of how chemical compounds are partitioned between the particle and gas phases. Accordingly, we propose coupling a two-filter sampling method with a multi-technique analytical approach to fully characterize the particulate- and gas-phase compositions of combustion byproducts. The two-filter sampling method is designed to retain particulate matter (elemental carbon possibly covered in a surface layer of adsorbed molecules) on a first quartz fiber filter while letting the gas phase pass through and then trap the most volatile components on a second black-carboncovered filter. All samples thus collected are subsequently subjected to a multi-technique analytical protocol involving two-step laser mass spectrometry (L2MS), secondary ion mass spectrometry (SIMS), and micro-Raman spectroscopy. Using the combination of this two-filter sampling-multitechnique approach in conjunction with advanced statistical methods, we are able to unravel distinct surface chemical compositions of aerosols generated with different set points of a miniCAST burner. Specifically, we successfully discriminate samples by their volatile, semi-volatile, and nonvolatile polycyclic aromatic hydrocarbon (PAH) contents and
\end{abstract}

reveal how subtle changes in combustion parameters affect particle surface chemistry.

\section{Introduction}

Particulate matter (PM) produced by incomplete combustion of hydrocarbon-based fuels is often found associated with gas-phase compounds that include carbon and nitrogen oxides $\left(\mathrm{CO}, \mathrm{CO}_{2}\right.$, and $\left.\mathrm{NO}_{x}\right)$, along with a volatile fraction of organic species encompassing low-mass polycyclic aromatic hydrocarbons (PAHs). The presence of PAHs in the atmosphere is of great concern due to their carcinogenic and mutagenic potential (Kim et al., 2013). In fact, in the current European air quality legislation (European Fourth Air quality Daughter Directive 2004/107/EC), seven potentially harmful PAHs must, at least, be monitored, but restrictions on PAH concentrations are currently solely limited to benzo $[a]$ pyrene because of its recognized high toxicity (annual target value of $1 \mathrm{ng} \mathrm{m}^{-3}$ in the $\mathrm{PM}_{10}$ particulate-phase fraction; Pandey et al., 2011). However, it is the conjunction of the PM intrinsic physicochemical properties (e.g., nature of adsorbed PAH - Dachs and Eisenreich, 2000 - or water affinity) with pressure, temperature, hygrometric variations, or aging processes in the atmosphere that ultimately condition phase partitioning (free vs. bound fraction; Ravindra et al., 2006). Con- 
sequently, gas-phase PAHs which are relatively abundant yet known to bear only weak carcinogenic or mutagenic effects (Nisbet and LaGoy, 1992) - can further react through gas-phase processes or heterogeneous gas-PM exchanges to produce noxious oxy- or nitro-PAHs, for instance (Atkinson and Arey, 1994; Bandowe et al., 2014). PAHs emitted in exhausts, in either the gas phase or the particulate phase, must be analyzed and fully characterized at the same time to better understand their deposition mechanism or chemical transformation in the atmosphere and help ascertain their overall toxicity and impact on human health.

Several methods allowing the concomitant sampling of airborne PAHs in both the gas and particulate phases have been developed in recent decades (see, for example, the reviews by Pandey et al., 2011; Szulejko et al., 2014; Munyeza et al., 2019). The sampling protocol starts with the choice of a suitable sorbent material to either solely capture the vapor phase or solely retain PM. The former sorbent material mostly consists of polyurethane foam, resins, or graphitized carbon black mesh, whereas the latter is made of glass fiber, quartz fiber, or Teflon. The sorbents are placed in series, i.e., one after the other in the exhaust line. The soluble organic fraction is then extracted off-line from the sorbent (filter and/or resin) for subsequent gas chromatography-mass spectrometry (GC-MS) analyses (An et al., 2016; Elghawi et al., 2010; Sun et al., 2006). However, such solvent extraction methods exhibit recovery rates that are highly dependent upon the technique applied and the nature of PAHs a priori present. Accordingly, the GC-MS method, which relies on solvent extraction methods and calibration standards, is a time-consuming technique which is inherently more sensitive towards compounds having the greatest solubility. To circumvent this limitation, solvent-free methods have been recently developed based on thermal desorption (e.g., Villanueva et al., 2018), microwave-assisted desorption, or solid-phase micro-extraction (Szulejko et al., 2014). However, because sampling substrates may differ for PM and gas trapping, and often necessitate extraction techniques before characterization whose efficiencies are substrate-dependent, results obtained for the two phases may be difficult to compare and do not necessarily represent the whole PAH family making up either filter.

The CAST (Combustion Aerosol Standard) generator is often chosen to produce combustion-generated particles as it is easy to implement for systematic laboratory experiments, with the fuel and oxidation air flows being easily modifiable, enabling the investigation of a variety of chemistries. A miniCAST soot generator operated with different parameters as a source of combustion by-products can mimic some of the physicochemical properties of aircraft emissions, for example (Bescond et al., 2014; Marhaba et al., 2019; Moore et al., 2014). The observations derived from soot produced with this generator hence allows for potential real-world extrapolations, especially for combustion devices not equipped with after-treatment systems. Concomitantly sampling and characterizing the particulate and gas phases can thus be extremely useful when evaluating the impact of various sources (aircraft jet engines, wood combustion stoves, biomass burning) on the environment, as the gas-particulate partitioning conditions the overall reactivity. The two-filter method presented here can therefore be utilized to assess the efficiency of after-treatment systems, which are known to successfully remove the majority of particle-bound organic species from the surface, which results in increasing the elemental carbon (EC) to organic carbon (OC) contribution (Focsa et al., 2019). Time-of-flight aerosol mass spectrometry (ToF-AMS) has been used in the past by Ferge et al. (2006) and Mueller et al. (2015) to study PAH formation in a CAST generator at different oxidation flows. However, because only the particle phase has been analyzed, no information about the gas-phase composition can be derived in these experiments, which provide only an incomplete picture of the PAH family emitted in the exhausts.

In this work, we coupled a two-filter sampling method with a multi-technique analytical approach to fully characterize the particulate- and gas-phase compositions of combustion by-products. The two-filter collection method is intended to separate the particulate phase (front filter) from the gas phase (back filter) using fibrous filtration media (quartz fiber filters - QFFs). Once collected, the filters are analyzed using a multi-technique approach encompassing two-step laser mass spectrometry (L2MS), secondary ion mass spectrometry (SIMS), and micro-Raman spectroscopy. The L2MS technique has been extensively developed in our group (at the University of Lille, PhLAM laboratory) over the last decade to specifically probe the chemical composition of combustion by-products (Delhaye et al., 2017; Faccinetto et al., 2011, 2015; Moldanová et al., 2009; Popovicheva et al., 2017). Its high sensitivity and selectivity towards specific classes of compounds owing to different ionization schemes makes it an extremely valuable analytical tool that can be adapted to various samples. Using three different ionization wavelengths, it is possible to target various classes of compounds such as aromatic and aliphatic compounds. In addition, it is possible to reach a sub-femtomole limit of detection for PAHs upon specific desorption and ionization conditions (Faccinetto et al., 2011, 2015). The laser desorption process along with its coupling with the subsequent ionization step have been optimized over the years (Faccinetto et al., 2008; Mihesan et al., 2006, 2008) and ensure a soft removal (with minimum internal energy excess) of molecules adsorbed on the particle surface, while avoiding/limiting both their fragmentation and the in-depth damaging of the underlying carbon matrix (Faccinetto et al., 2015). L2MS spectra obtained in this work are additionally reinforced with the SIMS spectra of deposited miniCAST PM, with no sample preparation prior to the analyses since the particulate matter is preferentially trapped on the front filter. Subtle differences and similarities between front and back filters are revealed using mass spectrometry measurements (L2MS and SIMS) and the re- 
cently developed advanced statistical methodologies (Duca et al., 2019; Irimiea et al., 2018, 2019) based on principal component analysis (PCA).

\section{Experimental methods}

\subsection{Sample collection}

PM was sampled from the exhaust of a miniCAST generator (5201c) from Jing Ltd., as described previously in Yon et al. (2018), for example. Briefly, the miniCAST contains a propane-nitrogen flame with operating conditions controlled by the flow rates of propane, nitrogen, oxidation air $\left(Q^{\text {air }}\right)$, and dilution air. The working points used in this study (and others in this series; Bescond et al., 2014; Ouf et al., 2016; Yon et al., 2015) are detailed in Fig. 1. The main difference between these working points is the oxidation air flow and - for the SP4 point - nitrogen dilution, with an increasing oxidation air flow in the order $Q_{\mathrm{SP} 3}^{\text {air }}<Q_{\mathrm{SP} 2}^{\text {air }}<Q_{\mathrm{SP} 4}^{\text {air }}<Q_{\mathrm{SP} 1}^{\text {air }}$. Note that the sole dilution system in our experimental setup is that of the miniCAST generator itself (dilution airflow $20 \mathrm{~L} \mathrm{~min}^{-1}$, Fig. 1). The samples were deposited on quartz fiber filters (QFFs, Pall Tissuquartz QAT-UP 2500) using a specially designed sampling line (as illustrated in Fig. 1). A bypass line parallel to the sampling system has been added to ensure the miniCAST is maintained at atmospheric pressure. These QFFs are typically used in soot collection, for example in studies of aircraft PM (Delhaye et al., 2017), and are also employed when deriving organic carbon to total carbon ratios (OC/TC) of deposited soot (Bescond et al., 2016; Yon et al., 2015). QFFs are chosen because they proved to be highly efficient in capturing combustion emissions and they have a stable penetration curve among other filters when a range of physical parameters are varying in the sampling line (Zíková et al., 2015). From a theoretical point of view, it is very difficult to predict the collection efficiency of QFF for particles within the nanometer size domain, as generated in our combustion conditions (e.g., 99-166 nm modal diameter; Bescond et al., 2016). Filter collection efficiency is directly related to inertial impaction, direct interception, Brownian diffusion, and electrostatic forces (Brochot et al., 2019; Lindsley, 2016; Zíková et al., 2015). The resulting component of these forces is translated into a function that displays near$100 \%$ collection efficiency for particles smaller than $20 \mathrm{~nm}$ and larger than $300 \mathrm{~nm}$. The minimum collection efficiency, which is also referred to as the most penetrating particle size (MPPS), is obtained for the $100-300 \mathrm{~nm}$ size range. However, some studies showed that the MPPSs for QFF may peak around $60 \mathrm{~nm}$ and are possibly $<100 \mathrm{~nm}$ for other fibrous media (Brochot et al., 2019; Zíková et al., 2015). While these measured values are mostly influenced by both the flow velocity in the sampling line and the pressure drop at the surface of the filter, our flow conditions are close to those used in the work of Zíková et al. (2015). Consequently, we can roughly estimate that the MPPS for the "front filter" is below $100 \mathrm{~nm}$. Two filters were used for each sampling period: the front filter was a bare QFF placed in the exhaust line; the "back filter" was a QFF covered with a thin layer of black carbon (Pureblack 100 Carbon, Columbian Chemicals Company, specific surface area $80-150 \mathrm{~m}^{2} \mathrm{~g}^{-1}$ ) and placed $3.5 \mathrm{~cm}$ downstream of the front filter in the sampling line. Prior to sampling, the back filter was heated in an oven at $150^{\circ} \mathrm{C}$ for $16 \mathrm{~h}$ to remove pre-adsorbed species. Back filters thus produced were shown to yield no signal when analyzed by L2MS. Black carbon has previously been used as a matrix upon which pure PAHs were adsorbed for mass spectrometric analysis of soot surrogates (Faccinetto et al., 2011, 2015). In the same studies, black-carbon-covered filters were also used to sample the volatile fraction in flames. In the present study, the sampling line was designed to collect PM (including adsorbed species) on the front filter (FF) and to trap gasphase molecules from the remaining exhaust on the back filter (BF, Fig. 1). Note that particle buildup on the front filter could potentially increase its filtration efficiency and consequently trap PAHs that would instead pass through if the thickness of the PM collected on the front filter were not as high. Alternatively, species originally adsorbed on the PM can also be desorbed during the sampling and be retained on the back filter, which would lead to an overestimation of the gas-phase fraction (Paolini et al., 2017). However, our results will show that if this is the case, only specific PAHs of intermediate volatility are impacted by this phenomenon. In addition, this effect would not affect our statistical analysis (i.e., the covariance between mass peaks $(m / z))$ as similar diffusion behaviors can be expected within SP1 and SP3 samples, which exhibit similar soot porosity (e.g., the porosity of the soot material deposited on silicon wafers for SP1 and SP3 set points were calculated to be about $98.1 \%$ and $97.4 \%$, respectively; Ikhenazene et al., 2020). We therefore expect, from a statistical standpoint, that for each given $m / z$, the covariance will only negligibly be affected by diffusion. Sampling was performed for $20 \mathrm{~min}$ per working point. "Reference" samples (front and back filters) were collected by running the miniCAST generator for only 2 min under set point SP1 conditions. These samples represent pre-stabilization burner conditions. They were collected as a reference to ensure that the samples were not impacted by this early combustion phase, and the loading on these reference samples was much lower. After collection, samples were placed in watch glasses covered with $\mathrm{Al}$ foil and stored at $4{ }^{\circ} \mathrm{C}$ prior to analysis.

\subsection{Two-step (desorption-ionization) laser mass spectrometry}

Samples were analyzed using a two-step laser mass spectrometry (L2MS) technique built in-house (Mihesan et al., 2008). Briefly, the soot sample is introduced into the analysis chamber $\left(10^{-8} \mathrm{mbar}\right)$ via a preparation chamber, where it is pre-cooled by a constant flow of liquid nitrogen in the 


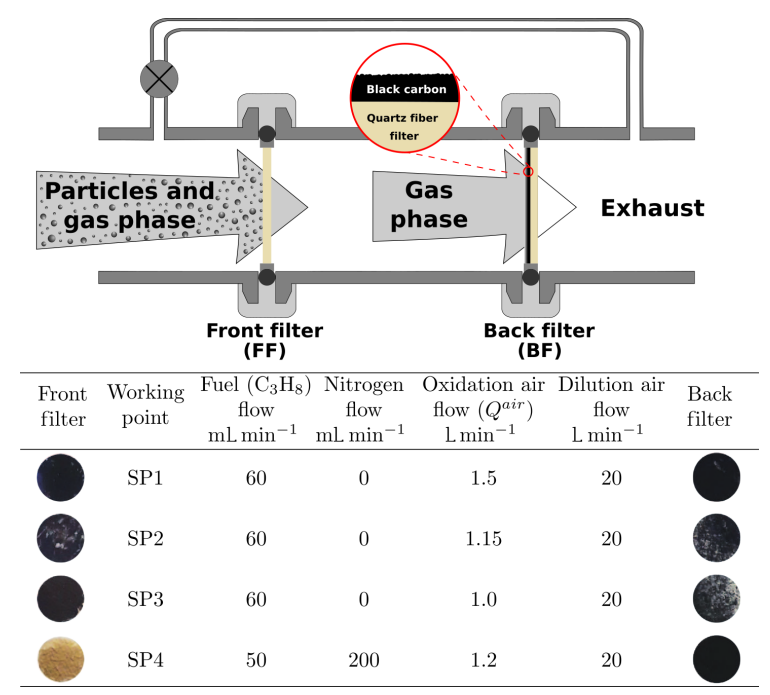

Figure 1. Schematic of the sampling line and photos of collected samples. The combustion parameters for the miniCAST burner are presented in the table.

sample holder to avoid the sublimation of the most volatile species. In the analysis chamber of the time-of-flight mass spectrometer (ToF-MS), the sample is irradiated at normal incidence by the beam of a frequency-doubled Nd:YAG laser (Continuum Minilite, $\lambda_{\mathrm{d}}=532 \mathrm{~nm}, 4 \mathrm{~ns}$ pulse width) shaped using a circular aperture and a $10 \mathrm{~cm}$ focal length planoconvex $\mathrm{CaF}_{2}$ lens to form a top hat beam, $0.8 \mathrm{~mm}$ diameter spot on the sample surface. Such irradiation is known to induce the desorption of neutral species from soot without affecting the carbon matrix (Faccinetto et al., 2011). All samples were analyzed with same desorption conditions $\left(\lambda_{d}=\right.$ $532 \mathrm{~nm}, 400 \mu \mathrm{J}_{\text {pulse }}{ }^{-1}, 80 \mathrm{~mJ} \mathrm{~cm}^{-2}$ i.e., $20 \mathrm{MW} \mathrm{cm}^{-2}$ ).

The desorbed plume propagates normally from the sample surface in between the extraction plates of the ToF-MS. The molecules from the desorbed plume are then ionized by either a resonant two-photon ionization R2PI (Haefliger and Zenobi, 1998; Mihesan et al., 2006; Zimmermann et al., 2001) process at $\lambda_{\mathrm{i}}=266 \mathrm{~nm}$ ( $4 \mathrm{~ns}$ width pulsed UV laser, Continuum Powerlite, $1 \mathrm{~mJ}$ pulse ${ }^{-1}$ ) or a single-photon ionization (SPI) process at $\lambda_{\mathrm{i}}=157 \mathrm{~nm}$ ( $5 \mathrm{~ns}$ width pulsed vacuum ultraviolet (VUV) excimer laser, Coherent ExciStar XS 200) or $\lambda_{\mathrm{i}}=118 \mathrm{~nm}$ (in-house built coherent nanosecond source). The ninth harmonic of the Nd:YAG laser $\left(\lambda_{i}=\right.$ $118.2 \mathrm{~nm}$ ) was generated by tripling the $355 \mathrm{~nm}$ output of a Continuum Surelite pulsed laser in a Xe cell (Hilbig, 1982; Popovicheva et al., 2017). For the two SPI wavelengths, the setup was optimized to the maximum output (i.e., maximum electric potential for the $157 \mathrm{~nm}$ excimer laser, and maximum pumping energy for the $355 \mathrm{~nm}$ laser; $34 \mathrm{~mJ}_{\text {pulse }}{ }^{-1}$ ) to maximize $118 \mathrm{~nm}$ conversion, at an estimated conversion efficiency of $0.01 \%$ (Butcher, 1999). The time delay between desorption and ionization is set to $100 \mu$ s by a digital delaypulse generator (Stanford DG535). Generated ions are then mass analyzed in a $1.72 \mathrm{~m}$ long reflectron ToF-MS (RM Jordan) with a mass resolution of $m / \Delta m 1000$. Ion detector signals are recorded using a digital oscilloscope (LeCroy Waverunner $9350 \mathrm{AM}$ ) at a time resolution of $4 \mathrm{~ns}$ per point. Each spectrum corresponds to an average of at least 200 desorption shots at different locations on the sample. A set of three spectra was obtained for each miniCAST sample (front and back filters) and each ionization scheme. Therefore, in total, 18 spectra were obtained for each miniCAST set point.

\subsection{Secondary ion mass spectrometry}

Time-of-flight secondary ion mass spectrometry analysis was conducted with the TOF.SIMS ${ }^{5}$ instrument from IONTOF $\mathrm{GmbH}$. Briefly, samples were introduced into the analysis chamber with a residual pressure of $10^{-8}$ mbar. The sample surface was bombarded by a $25 \mathrm{keV} \mathrm{Bi}{ }_{3}^{+}$ion beam with a current of $0.3 \mathrm{pA}$ in static mode. The $180 \mathrm{~s}$ acquisition time and 25 random scans per acquisition were used for an analyzed area of $500 \mu \mathrm{m} \times 500 \mu \mathrm{m}$ on the sample surfaces. Mass spectra were collected in both positive and negative polarities for at least three areas per sample. The mass resolution at $m / z 29$ is approximately 2700 . For this analysis samples are not cooled down. Ion signals in SIMS mass spectra were identified and calibrated using SurfaceLab 6 software from IONTOF GmbH. Positive spectra were calibrated with peaks $\mathrm{C}^{+}\left(m / z\right.$ 12.000), $\mathrm{CH}_{3}^{+}\left(m / z\right.$ 15.023), $\mathrm{C}_{7} \mathrm{H}_{7}^{+}(m / z$ 91.055), $\mathrm{C}_{16} \mathrm{H}_{10}^{+}\left(m / z\right.$ 202.078), and $\mathrm{C}_{19} \mathrm{H}_{11}^{+}(m / z$ 239.086). Negative spectra were calibrated with peaks at $\mathrm{C}^{-}(m / z 12.000), \mathrm{CH}^{-}$ ( $m / z$ 13.008), $\mathrm{O}^{-}$(m/z 15.995), $\mathrm{C}_{2}^{-}(m / z 24.000), \mathrm{C}_{4} \mathrm{H}^{-}$ $\left(m / z\right.$ 49.008), and $\mathrm{C}_{8} \mathrm{H}^{-}(m / z$ 97.008). A set of five spectra was obtained for each miniCAST sample (FF and BF) and each polarity. Therefore, in total, 20 spectra were acquired for each miniCAST set point.

\subsection{Raman micro-spectroscopy}

Raman analyses were performed with an inVia reflex spectrometer (Renishaw) equipped with an Olympus microscope (BXFM) (Chazallon et al., 2014). The spectra presented in this work were obtained by irradiation with a $514 \mathrm{~nm}$ laser with a nominal power of $150 \mathrm{~mW}$. The laser power was reduced to avoid thermal effects at the sample surface. Using a lens with $20 \times$ magnification (N.A. 0.5), the laser was focused on the sample surface to a $3.0 \mu \mathrm{m}$ diameter spot. The spectrometer was calibrated using the Stokes Raman signal of pure $\mathrm{Si}$ at $520 \mathrm{~cm}^{-1}$. Raman spectra of spectral resolution $12 \mathrm{~cm}^{-1}$ were collected at four different spots on each sample using integration times of $60 \mathrm{~s}$ with 10-20 scans accumulated per spectrum.

\subsection{Multivariate data analysis: principal component analysis (PCA)}

PCA is a technique used to highlight variation and patterns in a dataset, and in this case it was used to reveal the differ- 
ences in chemical composition of the samples, and in particular between (i) front and back filters and (ii) miniCAST set points. PCA is very convenient to outline the subtle differences between datasets, since it reduces the dimensionality of complex data while preserving most of the information. PCA was applied to each of the five datasets (three L2MS ionization wavelengths and two SIMS polarities) following the procedure detailed in Popovicheva et al. (2017), Irimiea et al. (2018), and Duca et al. (2019). Further information can also be found in Sect. S1 in the Supplement. Briefly, each mass spectrum was represented by the integrated areas of a selected number of mass peaks in the spectrum. The number of selected mass peaks was 66, 105, and 60 in L2MS mass spectra recorded at $\lambda_{\mathrm{i}}=266,157$, and $118 \mathrm{~nm}$, respectively, and 138 and 70 in SIMS mass spectra recorded in positive and negative polarity, respectively. PCA analyses were performed using a covariance matrix, i.e., each dataset was organized into a matrix containing observations (i.e., samples) arranged in rows and variables (i.e., peak integrated areas) arranged in columns. Principal components (PCs) were constructed as linear combinations or mixtures of the initial variables (peak integrated areas). The physical meaning of all derived PCs can be inferred from the contribution of the various molecular species to the loadings, i.e., by determining the relative importance of each mass peak integrated area to the main variance in the dataset. Scree plots and loadings for all L2MS PCA analyses discussed in this article can be found in the Supplement (Figs. S1 and S2). It should be further noted that initial PCA tests included reference samples (in both L2MS and SIMS PCAs). This preliminary step resulted in PC1 (the largest variance in the dataset) being dominated by the variance between the reference samples (front and back filters) and all other samples, confirming that the 2 min prestabilization deposition does not influence the spectra of the various set points measured (see Sect. 2.1). After this confirmation step, the reference samples were removed from the covariance matrix used to perform the PCA and therefore are not presented in the following sections.

\section{Results and discussion}

\subsection{L2MS analysis}

\subsubsection{Mass spectra obtained by L2MS at individual ionization wavelengths}

L2MS mass spectra of samples SP1, SP2, SP3, and SP4 (for both front and back filters) produced at three different ionization wavelengths $(266,157$, and $118 \mathrm{~nm})$ are discussed in this section. Mass spectra obtained with the $266 \mathrm{~nm}$ ionization wavelength are presented in Fig. 2, whereas results obtained for 157 and $118 \mathrm{~nm}$ are both presented in Fig. S3.

Upon $266 \mathrm{~nm}$ ionization, all mass spectra are dominated by signals attributed to aromatic species, and more specif- ically to PAHs (Fig. 2). An important advantage of L2MS is to generate, for the most part, fragment-free mass spectra while maintaining a high signal-to-noise ratio, due to the controlled desorption and ionization fluences (Faccinetto et al., 2011). On all mass spectra generated with the $266 \mathrm{~nm}$ ionization wavelength, the lightest detected PAH is naphthalene $\left(\mathrm{C}_{10} \mathrm{H}_{8}^{+}, m / z\right.$ 128).

On front filters ( $\lambda_{i}=266 \mathrm{~nm}$, Fig. 2), the heaviest detected mass varies from sample to sample: $\mathrm{SP} 1_{\mathrm{FF}}-m / z 400, \mathrm{SP} 2_{\mathrm{FF}}$ $-m / z$ 546, $\mathrm{SP} 3_{\mathrm{FF}}-m / z$ 546, and $\mathrm{SP} 4 \mathrm{FF}-m / z$ 522. The base peak is at $m / z 202$ for $\mathrm{SP} 2_{\mathrm{FF}}, \mathrm{SP} 3_{\mathrm{FF}}$, and $\mathrm{SP} 4_{\mathrm{FF}}$ and at $m / z 178$ for $\mathrm{SP} 1_{\mathrm{FF}}$. One can observe that the increase in oxidation air flow $\left(Q_{\mathrm{SP} 3}^{\text {air }}<Q_{\mathrm{SP} 2}^{\text {air }}<Q_{\mathrm{SP} 4}^{\text {air }}<Q_{\mathrm{SP} 1}^{\text {air }}\right)$ results in a significant variation in the shape of the mass spectra. In the SP1 regime, most of the signal comes from three- and four-ring PAHs, while the heavier PAHs are less conspicuous. Regimes with the lowest oxidation air flow tend to produce more of the heavier PAHs, although the increase in contribution for each mass is not the same. For samples SP2 $2_{\mathrm{FF}}$ and $\mathrm{SP} 4_{\mathrm{FF}}$, most of the PAHs are concentrated in the mass range $m / z$ 178-350 $\left(\mathrm{C}_{14} \mathrm{H}_{10}^{+}-\mathrm{C}_{28} \mathrm{H}_{14}^{+}\right)$, with comparable relative intensities. However, the SP3 regime has high peak intensities for $\mathrm{C}_{14} \mathrm{H}_{10}^{+}\left(m / z\right.$ 178), $\mathrm{C}_{16} \mathrm{H}_{10}^{+}(m / z 202), \mathrm{C}_{18} \mathrm{H}_{12}^{+}$ $(m / z 228)$, and $\mathrm{C}_{20} \mathrm{H}_{12}^{+}(m / z 252)$, while the relative contributions of heavier PAHs remain comparable. Literature data converge towards the fact that the SP3 set point is distinct from the others in that (i) the organic-to-total carbon ratio is higher ( $87 \%$ versus $\leq 47 \%$ for the other set points), and (ii) the crystallites of the particles produced in these conditions are significantly smaller and form a distinct disordered arrangement exhibiting many carbon edges (Bescond et al., 2016; Marhaba et al., 2019; Ouf et al., 2016; Yon et al., 2015). Such smaller crystallites suggest that SP3 may undergo nucleation and growth processes different from those of the other set points, subsequently leading to distinct chemical compositions (e.g., different isomeric distributions) of the PM. The relative ion signals observed between the front and back filters hence depend upon the relative volatilities and the response of the chemical compounds present on the samples to the $266 \mathrm{~nm}$ R2PI L2MS.

On back filters $\left(\lambda_{i}=266 \mathrm{~nm}\right.$, Fig. 2), the signal is mostly concentrated in a low mass region. Mass spectra of all back filters are dominated by $m / z 128$ (naphthalene, $\mathrm{C}_{10} \mathrm{H}_{8}$ ). The spectrum of $\mathrm{SP} 4_{\mathrm{BF}}$ shows more peaks of higher masses than what is observed on other samples. The first aromatic compound visible on all samples is benzene $(\mathrm{m} / \mathrm{z} 78)$; however its intensity is drastically reduced for both $\mathrm{SP} 2_{\mathrm{BF}}$ and $\mathrm{SP} 3_{\mathrm{BF}}$ compared to that of $\mathrm{SP} 1_{\mathrm{BF}}$ or $\mathrm{SP} 4_{\mathrm{BF}}$. The same trend is observed for aromatic compounds lighter than $m / z$ 128. Oxidation air flows associated with set points SP4 and SP1 thus resulted in the formation of more of the smallest-sized aromatic species $(m / z, 78-128)$.

The various miniCAST set points exhibit different PAH mass distributions on their front and back filters, which likely relates to the different volatility properties of PAHs and prob- 


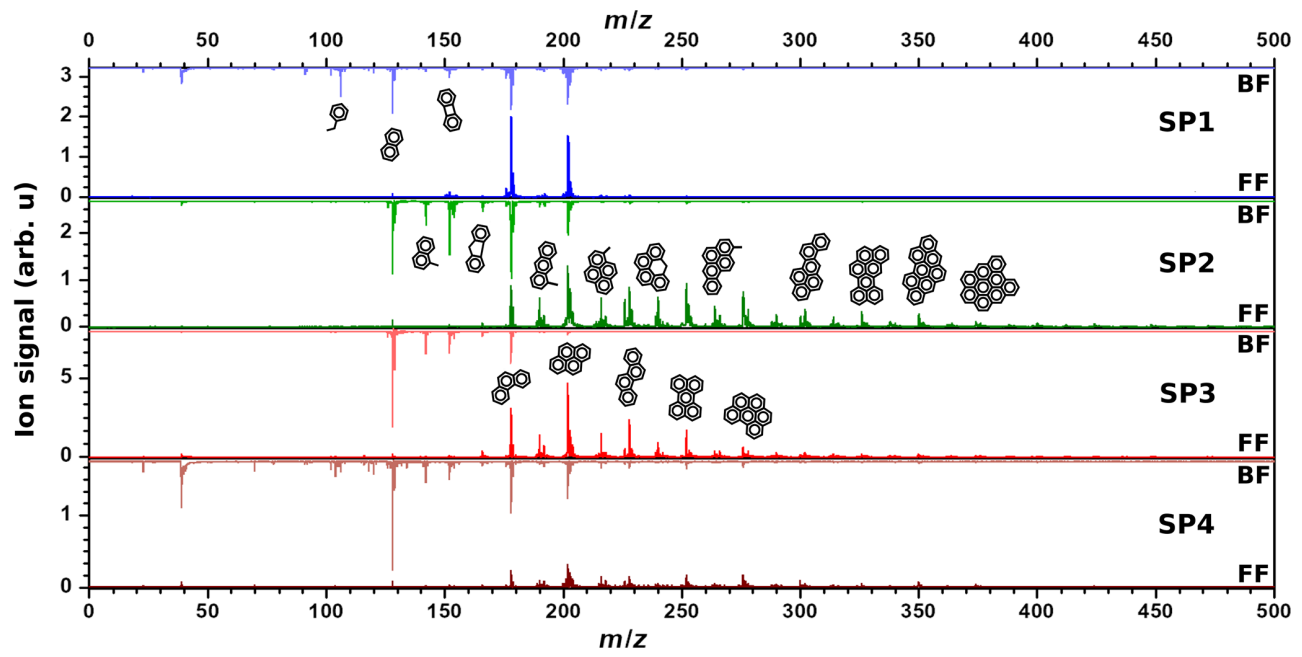

Figure 2. Comparison between mass spectra for SP1, SP2, SP3, and SP4 samples recorded with $\lambda_{\mathrm{i}}=266 \mathrm{~nm}$ for front filters (lower spectra) and back filters (upper spectra). Note that four different areas have been averaged to yield each of these spectra. Proposed structural formulae based on molecular formulae obtained from mass spectra are also shown.

ably affects their subsequent trapping on front and back filters. Distinct volatility properties have been observed in the past on particles originating from wood combustion by Bari et al. (2010), who classified the PAHs on the basis of their number of aromatic rings resulting in the detection of three different PAH categories. The authors classified the PAHs consisting of two aromatic rings as volatiles as they were mostly found in the gas phase, while those made of three and four rings were classified as semi-volatiles. PAHs comprising more than four rings were classified as non-volatile as they were observed in the PM in their study. Note that slightly different classes have also been defined elsewhere in the literature (An et al., 2016; Elghawi et al., 2010; Sun et al., 2006). In our study, we largely found compounds consisting of one and two aromatic rings on back filters, while PAHs of $m / z$ 176-242 were found on both back and front filters and those of $m / z \geq 252$ predominantly on front filters. Such PAH partitioning between front and back filters is in line with the work of Bari et al. (2010). Similarly, we categorized the PAH distributions found on miniCAST samples into volatile, semi-volatile, and non-volatile fractions (Fig. 3), where the volatile fraction here encompasses aromatic species made of one to two aromatic rings $(m / z 78-166)$, the semi-volatile fraction comprises PAHs with a mass range of $m / z$ 176-242, and the non-volatile fraction includes PAHs of $m / z=252$. The boundaries of these intervals have been refined using the representation of Fig. 3 in which the "contrast function" defined as the $\frac{S_{\mathrm{FF}}-S_{\mathrm{BF}}}{S_{\mathrm{FF}}+S_{\mathrm{BF}}}$ ratio is represented for the $266 \mathrm{~nm} \mathrm{~L} 2 \mathrm{MS}$ data, where $S_{\mathrm{FF}}$ and $S_{\mathrm{BF}}$ are the ion signals associated with a mass peak on the front filter and the back filter, respectively. This representation clearly underlines that small aromatic species are found solely on the back filters, whereas large PAHs are mostly on the front filters.

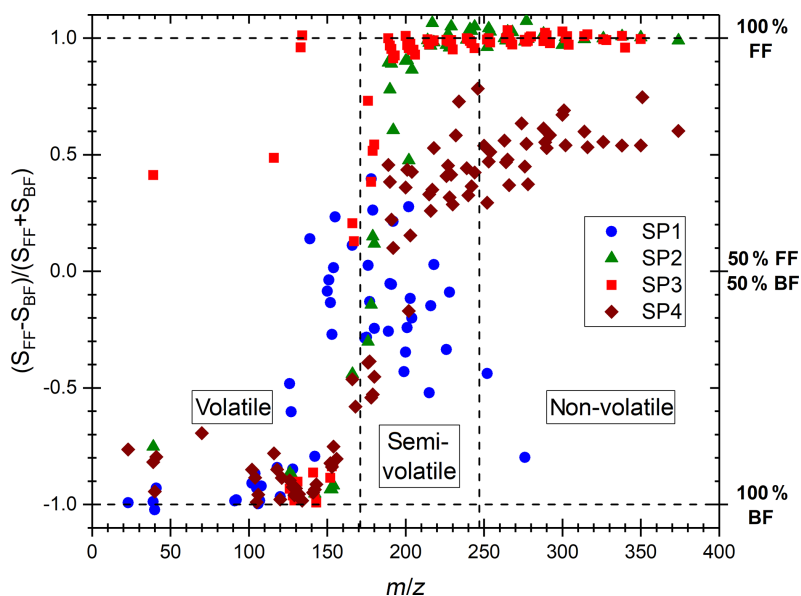

Figure 3. "Contrast plot" representing the variation in PAH signal detected with L2MS at $\lambda_{\mathrm{i}}=266 \mathrm{~nm}$ for the four miniCAST set points. Values on the $y$ axis correspond to the partitioning of the species between the front filters and back filters: -1 indicates that the species are all found on the $\mathrm{BF},+1$ that they are all found on the $\mathrm{FF}$, and 0 that they are equally partitioned on both filters.

The total PAH signal derived from L2MS measurements $\left(\lambda_{\mathrm{i}}=266 \mathrm{~nm}\right)$ can be further refined according to the PAH mass range distribution present on each sample (Fig. 4) as previously defined in Fig. 3. Delhaye and coworkers showed that the total PAH signal in mass spectra obtained with $\lambda_{\mathrm{i}}=$ $266 \mathrm{~nm}$ can be indicative of the amount of organic carbon in aeronautical soot samples because of the good agreement between total PAH mass signal and OC/TC values derived by a commonly used thermo-optical protocol (see Fig. 7 in Delhaye et al., 2017). In Fig. 4, the total PAH signal, corresponding to the sum of all peaks attributed to PAHs in the 


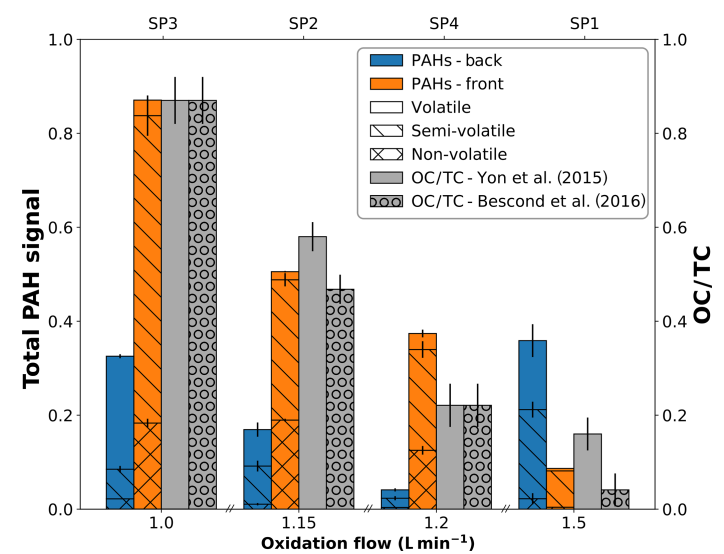

Figure 4. Variation in total PAH signal detected with L2MS at $\lambda_{\mathrm{i}}=$ $266 \mathrm{~nm}$ on front (orange) and back (blue) filters plotted as a function of oxidation air flow. The PAH contribution is divided into adsorbed species non-volatile $(m / z \geq 252)$, semi-volatile $(m / z 176-$ $242)$, and volatile $(m / z 78-166)$ fractions. OC/TC values reported in the literature are plotted in grey for comparison.

$266 \mathrm{~nm}$ normalized mass spectra, is plotted against the oxidation air flow and is further compared to the OC/TC values given in Bescond et al. (2016) and Yon et al. (2015). According to these studies, SP1 has the lowest $\mathrm{OC} / \mathrm{TC}$ ratio at $4.1 \%$, followed by SP4 (OC/TC $22.1 \%)$, SP2 (OC/TC $46.8 \%)$, and SP3 (OC/TC $87 \%)$. Slightly different values for SP2 (OC/TC 58.3\%) and SP1 (OC/TC 16.2\%) are given by Yon et al. (2015), but the same overall trend is maintained. The same evolution with oxidation air flow was evidenced for the PAH-to-soot ratio in Moore et al. (2014) using a different method (photoelectric aerosol sensor). Figure 4 shows that the total PAH signal measured by mass spectrometry $\left(\lambda_{\mathrm{i}}=266 \mathrm{~nm}\right)$ on front filters (orange bars) follows the same trend as the OC/TC ratios measured by the thermooptical protocol for the same miniCAST set points (Bescond et al., 2016; Yon et al., 2015). Although the total PAH signal on back filters (blue bars, Fig. 3) also follows the trend observed on front filters for samples $\mathrm{SP} 3_{\mathrm{BF}}, \mathrm{SP} 2_{\mathrm{BF}}$, and $\mathrm{SP} 4_{\mathrm{BF}}$ (decreasing PAH signal with increasing oxidation air flow), total $\mathrm{PAH}$ signal of $\mathrm{SP} 1_{\mathrm{BF}}$ is high compared to that of $\mathrm{SP} 1_{\mathrm{FF}}$. This is likely due to the nature of its PAH content for this set point, which likely includes more volatile and semi-volatile aromatic species.

In order to access other classes of molecules, the miniCAST set points have been also analyzed using 157 and $118 \mathrm{~nm}$ ionization wavelengths. The majority of PAHs were also detected with SPI at $157 \mathrm{~nm}$ for both front and back filters, albeit at a lower signal intensity (as can be seen by comparing the two sets of spectra in Figs. 2 and S3). The overall shape changes due to the different ionization efficiencies of PAHs from R2PI at $266 \mathrm{~nm}$ and SPI at $157 \mathrm{~nm}$. At lower masses, additional peaks with prominent features at $m / z 28$, 43,55 , and 69 are present and are assigned to aliphatic frag- ment ions, which could result from multi-photon ionization processes. Analysis of the peak at $m / z 31$ suggests the presence of heteroatoms in the fragments as it cannot be assigned to a $\mathrm{C}_{n} \mathrm{H}_{m}^{+}$hydrocarbon formula. The series of $m / z$ 91, 103, and 115 corresponds to fragments $\left(\mathrm{C}_{7} \mathrm{H}_{7}^{+}, \mathrm{C}_{8} \mathrm{H}_{7}^{+}, \mathrm{C}_{9} \mathrm{H}_{7}^{+}\right)$, which are attributed to alkylbenzene species (McLafferty and Turecek, 1993).

Mass spectra obtained with SPI at $118 \mathrm{~nm}$ (Fig. S3) show a high degree of fragmentation. In all cases, peaks at $m / z 23$ and 39 are due to the presence of trace amounts of the usual contaminants $\mathrm{Na}$ and $\mathrm{K}$. PAHs were detected on all samples, but the signal intensity is low due to a high fragmentation rate caused by the excess of energy at $\lambda_{\mathrm{i}}=118 \mathrm{~nm}$. Fragment ions at $m / z 50,51,52,53,63$, and 65 also suggest the presence of aromatic compounds. Series of highly unsaturated aliphatic compounds $\left(\mathrm{C}_{2 n} \mathrm{H}_{2}^{+}\right.$and $\left.\mathrm{C}_{2 n} \mathrm{H}_{4}^{+}, n=2-5\right)$ are present. Fragments of alkyl compounds $\left(\mathrm{C}_{n} \mathrm{H}_{2 n+1}^{+}\right)$were also found at $m / z 15,29,43,57,71,85$, and 99 , with a relatively low intensity compared to fragments of aromatic compounds. Another distinctive series - attributed to $\mathrm{C}_{n} \mathrm{H}_{2 n}^{+}$ fragments - was found at $m / z 28,42,56$, and 70 . These fragments may result from a McLafferty rearrangement involving alkene chains (McLafferty and Turecek, 1993).

In conclusion, our L2MS results for the three ionization wavelengths converge to show that heavy PAHs ( $m / z \geq 252$ ) are largely found on the front filters, whereas the volatile aromatic species (one to two rings) are solely detected on the back filters. This detailed mass spectrometry analysis coupled with our two-filter collection system shows very effective partitioning of the PM-gas phases on FF and BF and a clear dependence on the volatility of the molecules. We find that the total PAH content varies with the oxidative air flow, as shown in previous studies. Finally, this two-filter system allows us to evidence subtle differences in the chemical composition of the various miniCAST set points.

\subsubsection{Principal component analysis of L2MS spectra}

In order to better discriminate the chemical composition of the various samples, particularly (i) the front and back filters and (ii) the miniCAST set points, principal component analysis (PCA) was applied to mass spectra recorded for all three individual ionization wavelengths. A full description of this statistical method is provided in Sect. S1. Here, the covariance matrix was built from the integrated areas of all the detected peaks with a signal-to-noise ratio $(\mathrm{SNR})>3$. The physical meaning of all derived principal components can be inferred from the contribution of the various molecular species to the loadings (see Sect. S1 and Figs. 5b and S2). By identifying the molecular families contributing to this variance, we can interpret the PCA score plots (Fig. 5) and grasp the nature of the subtle chemical differences between the samples.

The loading and scree plots corresponding to the L2MS data generated with the $266 \mathrm{~nm}$ ionization wavelength are 
presented in Figs. 5b and S1a, respectively. They show that PC1 expresses the largest variance $(58.86 \%)$ in the dataset and differentiates samples having a large number of highmass PAHs (positive contribution: $m / z \geq 189$ ) from those containing more of low-mass aromatic species (negative contribution: up to three aromatic rings), especially naphthalene $(m / z$ 128). PC2 $(19.30 \%)$ denotes the relative contribution between high-mass PAHs (positive contribution: $m / z \geq 216$ ) bearing four and more aromatic rings and aromatic compounds containing up to $m / z 202$, especially $m / z 178$ and 202, and benzene and its alkyl derivatives. The dataset, in terms of PC1 and PC2, is illustrated in a score plot in Fig. 5a. According to PC1, the largest separation appears between sample groups SP2-4 $4_{\mathrm{FF}}$ and $\mathrm{SP} 1-4_{\mathrm{BF}}$. It can be attributed to the higher fraction of high-mass PAHs $(m / z \geq 189)$ relative to smaller aromatic species in $\mathrm{SP} 2-4 \mathrm{FF}$. The first conclusion is that our samples are mainly separated regarding their chemical composition (non-volatile and semi-volatile fractions vs. volatile fraction) because of the two-filter collection system rather than the miniCAST operating conditions. However, a refined observation in the PCs can help to interpret composition variations between the different set points. For back filters, the PC1 score decreases along with the oxidation air flow, indicating a greater contribution of small aromatic species, especially naphthalene, for lower-oxidation air flows. Data points for front filters generally display a positive PC2 component except for $\mathrm{SP} 1_{\mathrm{FF}}$, a phenomenon possibly explained by the very small fraction of non-volatile PAHs produced in this regime relative to $m / z 178$ and 202 . The almost constant score of PC2 for SP2-4 $4_{\mathrm{FF}}$, which is in contrast with the very different scores for the back filters (Fig. 5a), and the high contribution of semi-volatile species to the PC2 loadings (Fig. 5b) highlight that the ratios of semivolatile compounds vary between the front and back filters for the different set points. This observation suggests that the partitioning between the front and back filters is not only driven by thermodynamic conditions (volatility) but also by the nature of the soot matrix produced at the different set points. Note that details about the PCA applied to the 157 and $118 \mathrm{~nm}$ L2MS data can be found in the Supplement (Sect. S1). The statistical approach developed in this section confirms from a quantitative standpoint the descriptive results obtained in Sect. 3.1.1.

\subsection{SIMS analysis}

\subsubsection{Mass spectra obtained by SIMS}

SIMS measurements are complementary to L2MS analysis as they can provide insights into the compounds that preferentially produce negative ions. For the sake of comparison with L2MS results, SIMS measurements were first obtained in positive mode. Positive spectra of SP1, SP2, SP3, and SP4 samples are presented in Fig. $6(\mathrm{~m} / \mathrm{z}, 150-500$ range). All SIMS mass spectra feature significant fragmen-
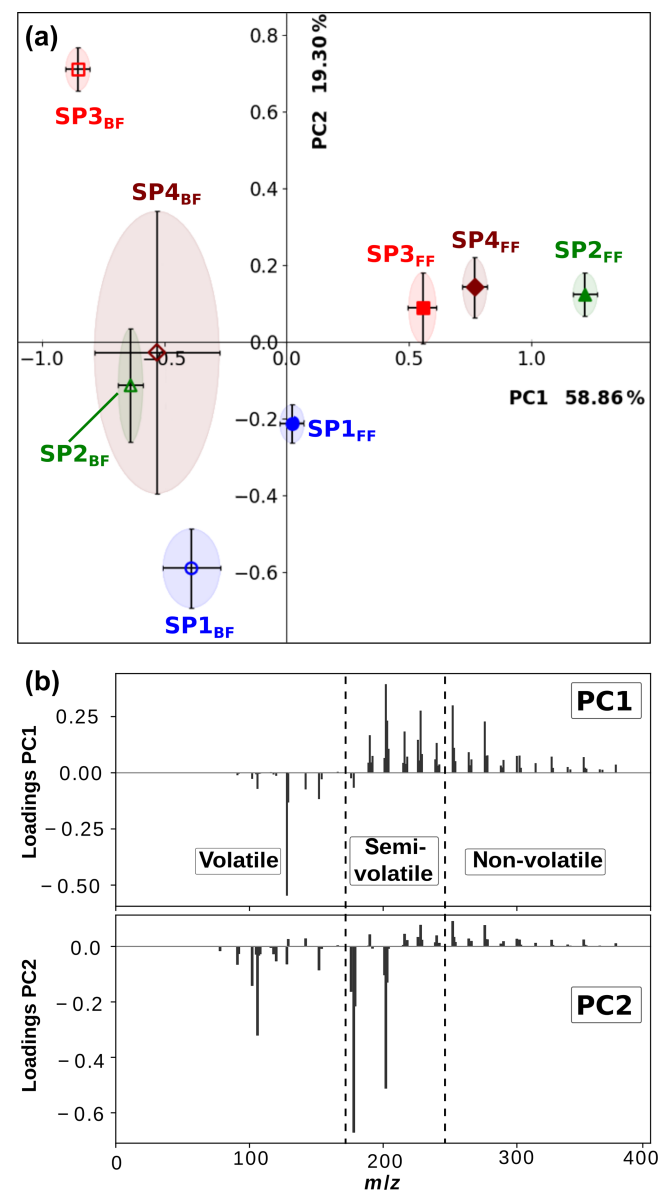

Figure 5. Score (a) and loading (b) plots of PC2 and PC1 derived from principal component analysis of the L2MS data obtained with $266 \mathrm{~nm}$ ionization.

tation, which is intrinsic to the technique and caused by the energetic primary ion beam. To start with front filter samples, and similarly to what has been observed in L2MS, the PAH distribution across samples varies with set points, the highest detected mass on $\mathrm{SP} 1_{\mathrm{FF}}, \mathrm{SP} 2_{\mathrm{FF}}, \mathrm{SP} 3_{\mathrm{FF}}$, and $\mathrm{SP} 4_{\mathrm{FF}}$ being $m / z 452, m / z 871, m / z 825$, and $m / z$ 908, respectively. SP1 $1_{\mathrm{FF}}$ shows a shorter high-mass PAH "tail" compared to other front filter samples. The high-mass PAH region observed in SIMS is in good agreement with that of L2MS, whereas the significant fragmentation observed in SIMS seems to impair the low-mass region (ca. $m / z<228$ ) more conspicuously and as a result makes SIMS and L2MS spectra look more distinct in this region. It is worth recalling that SIMS measurements are performed at room temperature, which contrasts with L2MS measurements that involve nitrogen cooling. This may potentially result in SIMS analyses providing an incomplete picture for some specific lowmass PAHs. The base peak of $\mathrm{SP} 2_{\mathrm{FF}}, \mathrm{SP} 3_{\mathrm{FF}}$, and $\mathrm{SP} 4_{\mathrm{FF}}$ samples is located at $m / z 239\left(\mathrm{C}_{19} \mathrm{H}_{11}^{+}\right)$, whereas $\mathrm{SP} 1_{\mathrm{FF}}$ exhibits its highest-intensity peak at $m / z 202\left(\mathrm{C}_{16} \mathrm{H}_{10}^{+}\right)$. The absolute intensity of the overall signal is the highest for $\mathrm{SP} 3_{\mathrm{FF}}$, fol- 
lowed by $\mathrm{SP} 2_{\mathrm{FF}}, \mathrm{SP} 4_{\mathrm{FF}}$, and $\mathrm{SP} 1_{\mathrm{FF}}$. Likewise, the total $\mathrm{PAH}$ contribution in each sample (i.e., summed areas of all peaks attributed to PAHs in positive mode) decreases with the oxidation air flow rate for front filters, as shown in Fig. 7, which indicates that the general trend previously shown with L2MS is also observed with SIMS. Consequently, the total PAH signal derived from SIMS measurement is also in line with OC/TC measurements obtained from thermo-optical methods (Bescond et al., 2016; Yon et al., 2015) for all front filter samples (Fig. 7). Here, non-volatile species are predominant on $\mathrm{SP} 3_{\mathrm{FF}}, \mathrm{SP} 2_{\mathrm{FF}}$, and $\mathrm{SP} 4_{\mathrm{FF}}$, while semi-volatile species constitute the main class of compounds observed on SP1 $1_{\mathrm{FF}}$. The prevalent class of chemical compounds in L2MS or SIMS mass spectra (Fig. 4 vs. Fig. 7) is linked to the ionization process $\left(\lambda_{\mathrm{i}}=266 \mathrm{~nm}\right.$ vs. $\mathrm{Bi}_{3}^{+}$ion beam). Semi-volatile compounds $(m / z, 178-228)$ are prevalent in spectra generated with the $266 \mathrm{~nm}$ ionization wavelength, whereas highmass aromatic compounds $(m / z, 250-500)$ dominate SIMS mass spectra. This suggests that miniCAST samples contain PAHs with a high stability in the high-mass range (i.e., stabilomers; Stein and Fahr, 1985), which are eventually less prone to fragmentation in SIMS with respect to other semivolatile compounds. Consequently, a smaller relative fraction of molecules is fragmented in L2MS, which leads to a more reliable PAH content determination in the semi-volatile mass range from their L2MS mass spectra compared to SIMS.

As to the PAH distribution observed on back filters, it is distinct from that of front filters in that the highest mass detected is $m / z 411$ on $\mathrm{SP} 1_{\mathrm{BF}}, m / z 570$ on $\mathrm{SP} 2_{\mathrm{BF}}, m / z 448$ on $\mathrm{SP} 3_{\mathrm{BF}}$, and $m / z 793$ on $\mathrm{SP} 4_{\mathrm{BF}}$ (i.e., the $m / z$ distribution of back filters is less spread out towards high masses). The total PAH signal now shows a different behavior to that observed on front filters (Fig. 7), where $\mathrm{SP} 4_{\mathrm{BF}}$ exhibits the highest PAH signal, followed by $\mathrm{SP} 2_{\mathrm{BF}}, \mathrm{SP} 1_{\mathrm{BF}}$, and $\mathrm{SP} 3_{\mathrm{BF}}$. Additionally, the PAH signal of $\mathrm{SP} 4_{\mathrm{BF}}$ determined by SIMS is higher than the one of its corresponding front filter, which is in contradiction to what has been derived from L2MS $\left(\lambda_{\mathrm{i}}=266 \mathrm{~nm}\right)$ spectra, where the front filter showed a much higher PAH signal. This behavior may originate from the nature of deposited PAHs on front and back filters, which may have different volatility and stability properties and hence will react differently to the energetic $\mathrm{Bi}_{3}^{+}$ion beam used in SIMS analysis.

Negative polarity mass spectra obtained for front and back filters are presented in Fig. S4. $\mathrm{H}^{-}$and $\mathrm{C}_{2}^{-}$fragment ions have the highest abundance in mass spectra of $\mathrm{SP} 1_{\mathrm{FF}}$ and $\mathrm{SP} 1_{\mathrm{BF}}$, whereas $\mathrm{SP} 2_{\mathrm{FF}}, \mathrm{SP} 3_{\mathrm{FF}}, \mathrm{SP} 4_{\mathrm{FF}}$, and $\mathrm{SP} 4_{\mathrm{BF}}$ are dominated by $\mathrm{H}^{-}$and $\mathrm{C}_{2} \mathrm{H}^{-}$. Similarly to that of the reference sample, spectra of $\mathrm{SP} 2_{\mathrm{BF}}$ and $\mathrm{SP} 3_{\mathrm{BF}}$ are dominated by $\mathrm{H}^{-}$ and $\mathrm{OH}^{-}$ions. The $\mathrm{C}_{n} \mathrm{H}^{-}$series is observed in mass spectra of SP2, SP3, and SP4 samples (front and back filters), with the intensity decreasing with the mass (for $n \geq 2$ ). To further understand this behavior, the relative abundances of the $\mathrm{C}_{n}^{-}$and $\mathrm{C}_{n} \mathrm{H}^{-}$fragments are plotted as a function of the oxidation air flow in Fig. 8. $\mathrm{C}_{n}^{-}$fragments are commonly con- sidered to be markers of the EC content (Duca et al., 2019; Pagels et al., 2013; Popovicheva et al., 2017). For instance, Pagels et al. (2013) used the sum of $\mathrm{C}_{n}^{-}(n=2-4)$ fragment signals as a marker of EC in aerosol time-of-flight mass spectrometer (ATOFMS) measurements for wood stove PM emissions, and the same marker ions have been used to discriminate diesel from biodiesel PM emissions by Popovicheva et al. (2017). $\mathrm{C}_{n} \mathrm{H}^{-}$fragments are commonly associated with OC contents (Ewinger et al., 1991; Le Roy et al., 2015), but it is worth noticing that both series have been detected in mass spectra of pure PAHs (Bentz et al., 1995; Le Roy et al., 2015). Here, the relative proportion of $\mathrm{C}_{n}^{-}$fragments increases with the initial oxidation air flow conditions on front filter samples and exhibits a similar contribution across front and back filter samples. It should be noted that the black carbon, pre-deposited on back filters, also contributes to the $\mathrm{C}_{n}^{-}$signal. However, for all miniCAST samples, the total $\mathrm{C}_{n}^{-}$ contribution is higher than that of the reference sample, suggesting that some proportion of $\mathrm{C}_{n}^{-}$on back filters originates from the deposited material. On the other hand, the $\mathrm{C}_{n} \mathrm{H}^{-}$ ion series shows a distribution across front and back samples akin to that of the total PAH signal (i.e., the total PAH signal in positive polarity; see Fig. 7). This positive correlation indicates a possible polyaromatic origin of the $\mathrm{C}_{n} \mathrm{H}^{-}$fragments. In order to better delineate the contributions of EC, PAHs, and other components to the $\mathrm{C}_{n}^{-}$carbon cluster series, Pearson correlation coefficients between all $\mathrm{C}_{n}^{-}$and $\mathrm{C}_{n} \mathrm{H}^{-}$ have been evaluated for the complete set of negative SIMS spectra. $\mathrm{C}_{n}^{-}(n=1-4)$ ions display high positive correlation $(r \geq 0.60)$ with a maximal value for $\mathrm{C}_{3}^{-}$and $\mathrm{C}_{4}^{-}(r=0.91)$. In contrast, this group of peaks is not correlated with the $\mathrm{C}_{5}^{-}$ fragment ion and is anticorrelated with all heavier carbon cluster ions ( $n \geq 6$ ). This first analysis shows that at least two components contribute to the $\mathrm{C}_{n}^{-}$signal. Furthermore, positive correlations are also found between the $\mathrm{C}_{n} \mathrm{H}^{-}(n=3-$ 12) fragments, but also between these $\mathrm{C}_{n} \mathrm{H}^{-}$ions and the $\mathrm{C}_{n}^{-}$ $(n=5-12)$ fragments. For better visibility, specific subsets of $\mathrm{C}_{n}^{-}$fragment ions ( $n=1-4$ and $\left.n=5-12\right)$ are plotted separately in Fig. 8c, d. Panel (c) shows that the ions with carbon numbers $n=1-4$ primarily contribute to the total $\mathrm{C}_{n}^{-}$signal, whereas panel (d) highlights the correlation between subset ions with carbon numbers $n=5-12$ and $\mathrm{C}_{n} \mathrm{H}^{-}$fragments. In addition, the similar distribution across front and back filters between $\mathrm{C}_{n} \mathrm{H}^{-}$fragment ions and total PAH signal which is a proxy for $\mathrm{OC}$ supports the fact that $\mathrm{C}_{n} \mathrm{H}^{-}$fragments can be considered a marker for $\mathrm{OC}$ in our soot samples. Therefore, while a predominant fraction of $\mathrm{C}_{n}^{-}$fragments $(n=1-4)$ are markers for EC, a non-negligible part $\left(\mathrm{C}_{n}^{-}\right.$with $\left.n \geq 5\right)$ also originates from the organic fraction present on our samples.

SIMS results confirm L2MS measurements regarding the organic carbon and more specifically the PAH contents and mass distributions for the various miniCAST set points. In contrast to L2MS, specific SIMS fragmentation patterns provide additional information about the presence of elemental 


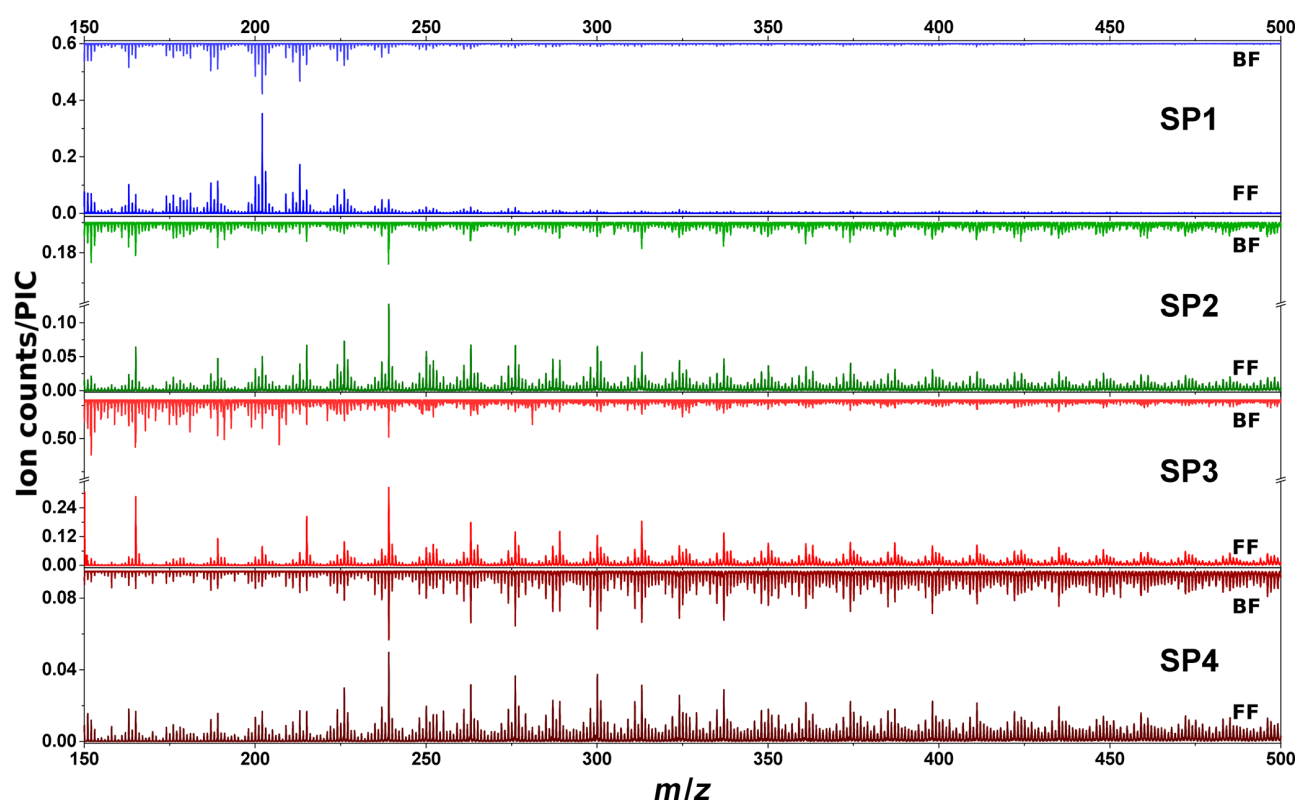

Figure 6. ToF-SIMS mass spectra of samples SP1, SP2, SP3, and SP4 obtained in positive polarity for front filters (lower spectra) and back filters (upper spectra). For visualization purposes, we focus on the $m / z \quad 150-500$ range. Note that for SP2 and SP3 samples front and back filters have different scales.

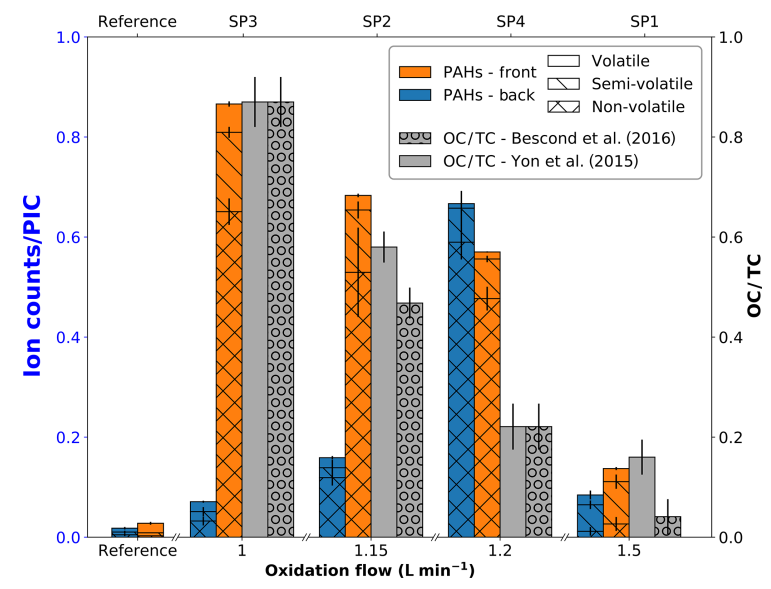

Figure 7. Total PAH signal detected with SIMS on front (orange) and back (blue) filters plotted as a function of oxidation air flow, along with OC/TC values reported in the literature for the same miniCAST set points. All values are normalized to the partial ion count (PIC) corresponding to the signal of all selected peaks.

carbon and outline the distinct elemental carbon vs. organic carbon contents for the different miniCAST set points.

\subsubsection{Principal component analysis of SIMS spectra}

PCA was applied to the positive-mode SIMS spectra. All hydrocarbon fragments and the most representative peaks for PAHs were chosen for the analysis (see Sect. S3). The PCA score plot for the first two components (PC1 and PC2, responsible for $92 \%$ of the variance) is presented in Fig. 9a, and their corresponding loadings are shown in Fig. 9c. PC1 represents $73 \%$ of the variance and is associated with small fragment ions with $m / z<160$ (e.g., $\mathrm{C}_{n} \mathrm{H}_{3}^{+}$with $n=1-3$, $\mathrm{C}_{n} \mathrm{H}_{m}^{+}$with $m>n, \mathrm{C}_{7} \mathrm{H}_{7}^{+}$, positive coefficients), and with polyaromatic species with $m / z \geq 165$ (negative coefficients). All back filter samples (containing gas-phase PAHs) except $\mathrm{SP} 4 \mathrm{BF}$ have positive $\mathrm{PC} 1$ scores, whereas all front filters but $\mathrm{SP} 1_{\mathrm{FF}}$ exhibit negative $\mathrm{PC} 1$ scores due to their high $\mathrm{PAH}$ contents. From this result, it can be determined that $\mathrm{SP} 3_{\mathrm{FF}}$ has the highest relative PAH content. Among front filters, $\mathrm{SP} 1_{\mathrm{FF}}$ has the smallest contribution from PAHs. SP $3_{\mathrm{BF}}$ has the highest contribution from fragments associated with both aliphatic and aromatic species. The negative contribution of PC2 (19\% of the variance) is associated with the hydrogenpoor fragments $\left(\mathrm{C}_{n} \mathrm{H}_{m}^{+}\right.$with $\left.m<n\right)$ and volatile and semivolatile PAHs ( $m / z$ 128-228) with the exception of $m / z 165$. The positive coefficients of PC2 are associated with aliphatic fragments (e.g., $\mathrm{C}_{n} \mathrm{H}_{m}^{+}$with $\left.m>n\right)$ and large PAHs $(m / z \geq$ 239). As most of the variance was contained in only two principal components $(92 \%)$, there are only two available criteria for differentiating between samples: PC1, corresponding to the amount of PAHs relative to fragments, and PC2, depending partially on the hydrogen content of fragments originating from aromatic and aliphatic species. $\mathrm{SP} 1_{\mathrm{FF}}$ and $\mathrm{SP} 1_{\mathrm{BF}}$ are located in almost the same position due to their positive scores in $\mathrm{PC} 1$ and negative scores in PC2, which corresponds to their limited high-mass PAH content and high fragment content on the one hand and small PAHs and hydrogen-rich fragments on the other hand. 

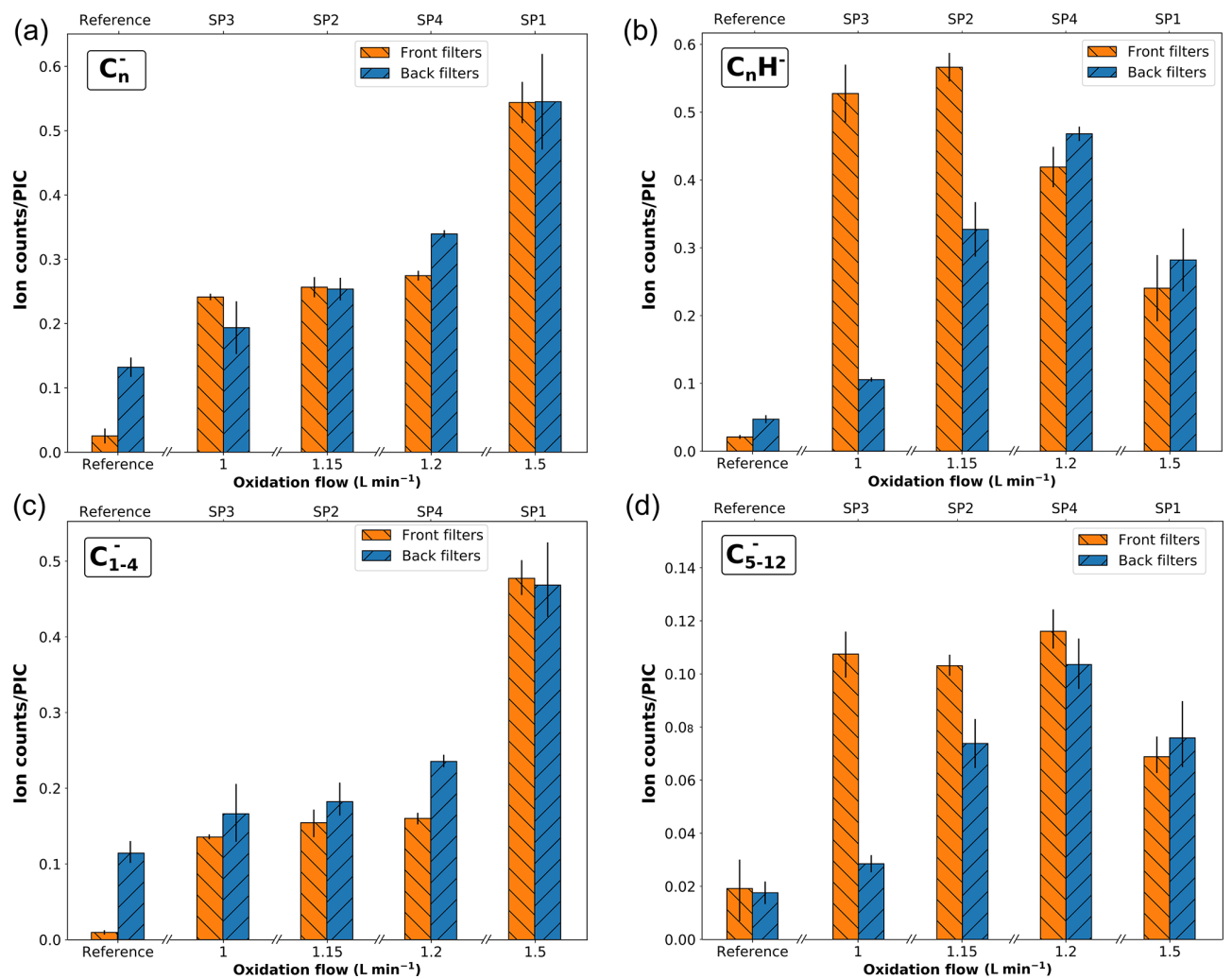

Figure 8. Variation in the signal of various markers, as derived from SIMS spectra. The panels represent the total peak areas of the following families: (a) $\mathrm{C}_{n}^{-}$, (b) $\mathrm{C}_{n} \mathrm{H}^{-}$, (c) $\mathrm{C}_{1-4}^{-}$, and (d) $\mathrm{C}_{5-12}^{-}$. All values are normalized to the partial ion count (PIC) corresponding to the signal of all selected peaks.

PCA was also applied to the negative-mode SIMS spectra for selected mass peaks, including carbon clusters $\mathrm{C}_{n}^{-}$, $\mathrm{C}_{n} \mathrm{H}^{-}$, and some oxygenated and nitrogenated fragment ions. The first two components were determined to represent more than $85 \%$ of the variance. The score plot of PC1 vs. $\mathrm{PC} 2$ is presented in Fig. 9b, along with their corresponding loadings (Fig. 9d). The first component, which accounts for over $67 \%$ of the variance, separates the samples containing low-mass carbon clusters $\mathrm{C}_{n}^{-}$(with $n \leq 3$ ) and nitrogen- and oxygen-bearing compounds (e.g., $\mathrm{CN}^{-}, \mathrm{C}_{3} \mathrm{NH}^{-}, \mathrm{CH}_{3} \mathrm{O}^{-}$) (positive $\mathrm{PC} 1$ ) from $\mathrm{C}_{n} \mathrm{H}_{0-2}^{-}$with $n \geq 4$, oxygenated, and nitrogenated fragments - negative contribution. The opposite contributions to PC1 of small carbon clusters in comparison to larger ones, with a transition size of $n=3-4$, strengthen their dichotomous origin as already discussed in Sect. 3.2.1. In the light of the score plots, $\mathrm{SP} 1_{\mathrm{FF}}$ and $\mathrm{SP} 1_{\mathrm{BF}}$ samples are characterized by low surface coverages where small carbon clusters are associated with the soot matrix and the black carbon, respectively, whereas the other samples feature PAHrich surfaces. PC2, accounting for $18 \%$ of the variance, separates data points based on the contribution from hydrocarbon compounds $\left(\mathrm{C}_{n} \mathrm{H}_{m}^{-}\right.$, negative $\left.\mathrm{PC} 2\right)$ and oxygen- and nitrogen-bearing fragments (positive contribution). PC2 dis- tinguishes $\mathrm{SP} 3_{\mathrm{BF}}$, and $\mathrm{SP} 2_{\mathrm{BF}}$ to a lesser extent, by their coverage in oxygen- and nitrogen-containing species.

To sum up, PCA on SIMS results confirms the existence of various families of carbon clusters on the PM that can be associated either with the soot matrix or with the surface $\mathrm{PAH}$ coating.

\subsection{Raman micro-spectroscopy analysis}

The two-filter system provides a unique opportunity to perform Raman spectroscopy on either the gas phase trapped on the back filter or the PM collected on the front filter. Raman spectra measured for each sample are presented in Fig. 10. All spectra for PM deposited on front filters are in very good agreement with those already measured for the same miniCAST set points (e.g., Ess et al., 2016), while back filter spectra are dominated by the absorption of the pre-deposited black carbon. Soot particles often exhibit distinct Raman signatures that can be used to distinguish samples mostly by their hybridization and nanostructure (e.g., stacking properties) compared to that obtained for a perfect graphite crystal, i.e., a crystal made of $\mathrm{sp}^{2}$-hybridized carbons and graphene sheets stacked with their surfaces parallel and slightly offset. When samples differ from perfect crystalline graphite, defects appear and can take the form of stacking disorder (such 

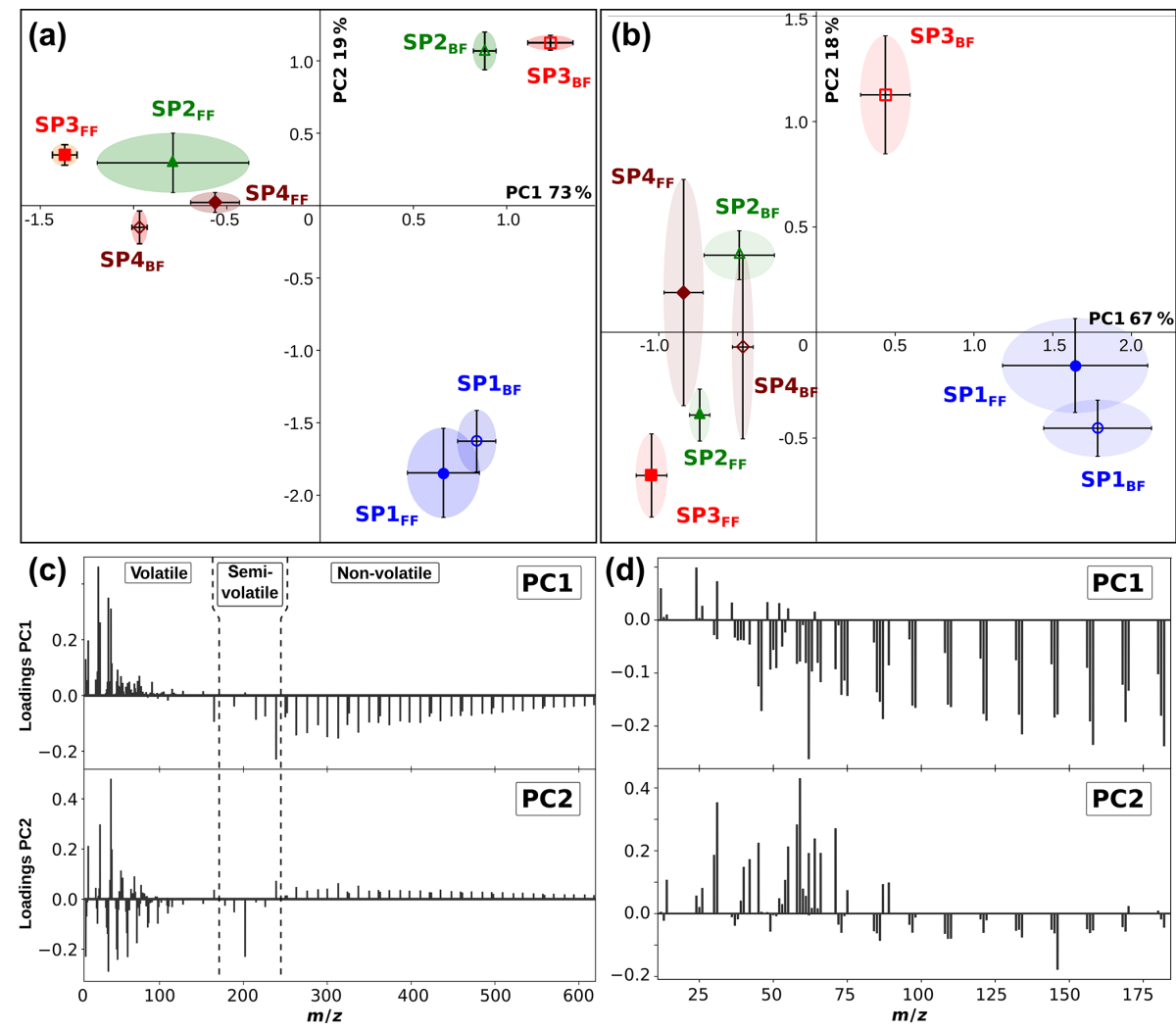

Figure 9. Score plots of PC1 and PC2 derived from positive (a) and negative (b) polarity SIMS mass spectra of miniCAST soot samples SP1, SP2, SP3, and SP4 (front and back filters). Loadings corresponding to the contribution of different species to PC1 and PC2 derived from positive (c) and negative (d) polarity SIMS mass spectra.

as in turbostratic arrangements where tortuosity reduces the stacking order), edge sites, missing atoms in the graphite lattice, or even altered local or semi-long-range arrangements of carbon atoms (Parent et al., 2016).

Both the fluorescence background (FB) and the soot Raman feature are observed to vary significantly with the set point (Fig. 10). The former refers to the baseline, whereas the latter refers to the two broadbands centered at 1356 and $1598 \mathrm{~cm}^{-1}$, termed D (for defect) and G (for graphite), which correspond to Raman scattering involving $E_{2 \mathrm{~g}}$ and $A_{1 \mathrm{~g}}^{\prime}$ symmetry, respectively (Ferrari and Robertson, 2000; Sadezky et al., 2005). FB is attributed to surface organic content (Cloutis et al., 2016) and is observed to decrease with increasing oxidation air flow for front filter samples $\left(\mathrm{FB}_{\mathrm{SP} 3}>\mathrm{FB}_{\mathrm{SP} 2}>\mathrm{FB}_{\mathrm{SP} 4}>\mathrm{FB}_{\mathrm{SP} 1}\right)$. This trend is even clearer when the fluorescence slope fitted as a straight line between 800 and $2200 \mathrm{~cm}^{-1}$ (Raman shift) is plotted against the total PAH signal determined in L2MS (Fig. 11). The linear fit $\left(R^{2}=0.992\right)$ obtained in Fig. 11 reflects the good agreement between the FB and the measured trend in total PAH signal. For back filter samples, the FB signal is nonexistent and spectra resemble that of black carbon except in the "valley" region (i.e., in between the two soot peaks).
Two conclusions can be drawn from these observations. First, when comparing fluorescence signals of back and front filter samples to PAH content, we can further refine our definition of organic content. Fluorescence is not just related to the total PAH signal, although this is a good marker of organic content. If it were, fluorescence would also be observed for back filter samples, in accordance with their relatively high gas-phase PAH contents. The lack of fluorescence signal on back filters, whose chemical composition is dominated by small PAHs, suggests that the fluorescence can be attributed mainly to non-volatile PAHs in the particulate phase, even though the heaviest mass detected in L2MS $(m / z$ 546) is still small to expect fluorescence with a $514 \mathrm{~nm}$ excitation wavelength (Mercier et al., 2019). Consequently, the interaction of PAHs with one another or with the PM surface seems to trigger the fluorescence excited at $514 \mathrm{~nm}$. Such a perturbative effect (e.g., aggregate formation) on the luminescence has been observed in solutions (Nakagawa et al., 2013).

Information on soot nanostructure ordering can be derived from the $I(\mathrm{D}) / I(\mathrm{G})$ height ratio, whose increase in intensity reflects a higher degree of order for soot made of crystallites $\left(L_{a}\right)$ smaller than $2 \mathrm{~nm}$ (Ess et al., 2016; Ferrari and Robertson, 2000). The intensity of the valley region between the two peaks $\left(1440-1540 \mathrm{~cm}^{-1}\right)$ provides insights into the pres- 

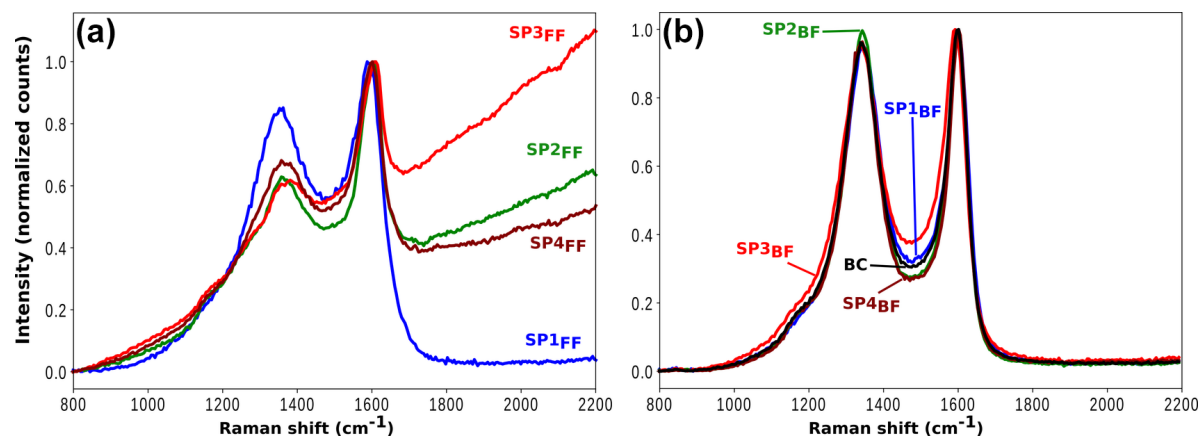

Figure 10. Raman spectra of SP1 (blue), SP2 (green), SP3 (red), and SP4 (brown) samples on front filter (a) and back filter (b). For all samples, plots are normalized to the maximum intensity of the $\mathrm{G}$ band. The spectrum of pure black carbon (BC) deposited on a QFF is plotted in black in panel (b) for comparison.
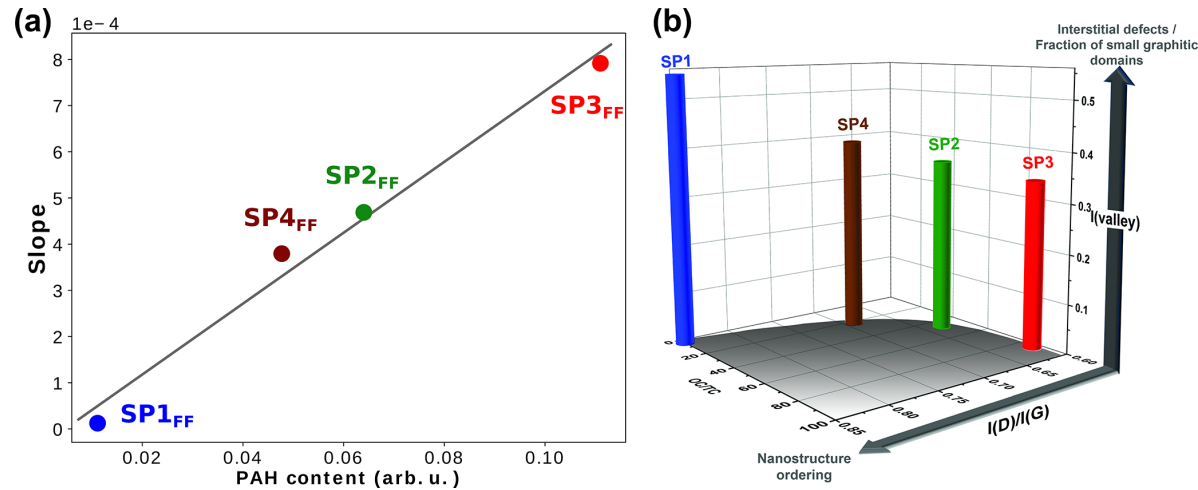

Figure 11. (a) Fluorescence slopes extracted from Raman spectra of SP1 $1_{\mathrm{FF}}-$ (blue), $\mathrm{SP} 2_{\mathrm{FF}}$ (green), $\mathrm{SP} 3_{\mathrm{FF}}$ (red), and $\mathrm{SP} 4_{\mathrm{FF}}(\mathrm{brown})$ plotted against total PAH content measured in L2MS (in terms of ion signal) in front filter samples, (b) 3-D bar plot showing the evolution of the intensity of the "valley" between the two D and G bands and that of the $I(\mathrm{D}) / I(\mathrm{G})$ height-ratio with organic content (OC/TC ratio) in front filter samples.

ence of interstitial defects which may distort the lattice structure (Ess et al., 2016; Ferrari and Robertson, 2000; Sadezky et al., 2005) or into the occurrence of small graphitic domains (Parent et al., 2016). For comparison purposes, Raman spectra measured for front filters (Fig. 11a) have been subsequently baseline-subtracted and normalized to the $\mathrm{G}$ band before interpretation. Figure $11 \mathrm{~b}$ shows the evolution of the $I(\mathrm{D}) / I(\mathrm{G})$ height ratio and that of the intensity of the valley region with the OC/TC ratio for each set point. This 3-D bar plot confirms that the nanostructure order $(I(\mathrm{D}) / I(\mathrm{G})$ height ratio) increases with decreasing $\mathrm{OC}$ content; i.e., the degree of order in the large polyaromatic network is higher under SP1 conditions (i.e., at higher oxidation air flow). This is in agreement with the analysis of Ess et al. (2016) of soot produced at set points SP1, SP2, and SP3. Furthermore, a similar behavior with the oxidation air flow has been observed through an analogous Raman tracer (AD1/(AG+AD2)) involving the integrated band areas (Carpentier et al., 2012), from soot consisting of polyaromatic units poorly linked together (analogous to $\mathrm{SP} 3_{\mathrm{FF}}$ ) to soot made of cross-linked structures with aliphatic bridges (analogous to $\mathrm{SP} 1_{\mathrm{FF}}$ ). Fig- ure $11 \mathrm{~b}$ shows that the SP1 set point produces soot composed of a larger polyaromatic network (larger crystallite size) and a greater fraction of small interconnected graphitic domains (high valley intensity) compared to $\mathrm{SP} 3_{\mathrm{FF}}$. These results are in line with what has been previously observed for such miniCAST soot particles (Marhaba et al., 2019; Ouf et al., 2016), where the SP3 set point produced particles with very small crystallites $(0.48-0.6 \mathrm{~nm})$ and the greatest tortuosity/disordered structure (HRTEM) among all miniCAST samples.

\section{Conclusions}

Combustion by-products (PM and gas phase) produced by a miniCAST generator are first separated and then characterized using a two-filter collection method and a multitechnique analytical-statistical protocol. Front and back filters thus generated are representative of the exhaust stream and are subsequently analyzed through first an original L2MS technique featuring three ionization schemes, followed by SIMS, and last micro-Raman spectroscopy. The 
three-wavelength L2MS scheme is employed in our study to target specific classes of compounds. We evidence the presence of aliphatic compounds and specific fragment ions using a $118 \mathrm{~nm}$ ionization source and we can focus on aromatic species using instead a $266 \mathrm{~nm}$ laser. Aromatic species were detected in all mass spectra (L2MS and SIMS). When combined with advanced statistical methods (PCA), mass spectrometry datasets revealed how different all samples were. Based on the PAH classification of Bari et al. (2010), we were able to discuss aromatics distribution across front and back filters in terms of volatile (one to two rings), semi-volatile (three to four rings), and non-volatile PAHs (larger than four rings). We determined that $P M$ is essentially sampled on front filters, whereas the dominant compounds trapped on all back filters were volatile PAHs regardless of the combustion conditions. The good separation between the two phases confirmed the high particle collection capability of QFF front filters. PCA revealed that distinct amounts of volatile compounds were present in samples produced with different combustion parameters. Specifically, changes in oxidation air flow conditions in the miniCAST resulted in notable changes in the mass distribution for both front and back filters. L2MS results at $266 \mathrm{~nm}$ indicated that low oxidation air flow conditions (SP2 and SP3) produced more semi-volatile and nonvolatile compounds in the exhaust stream. The addition of quenching gas $\left(\mathrm{N}_{2}\right)$ in the miniCAST combustion conditions (SP4) lessened the difference between front and back filters which featured more homogeneous mass spectra. Complementary micro-Raman spectroscopy analyses not only confirmed the relationship between the underlying fluorescence and the total PAH signal determined by mass spectrometry, but also identified as non-volatile the nature of PAHs involved in the fluorescence and detected in the particulate phase. Finally, all analyses confirmed the validity of total PAH signal as a proxy for the organic content (OC) commonly detected in thermo-optical measurements (Bescond et al., 2016; Yon et al., 2015). Accordingly, the total PAH signal measured by mass spectrometry was observed to decrease with increasing oxidation air flow conditions in the miniCAST. The two-filter collection method in conjunction with our multi-technique analytical-statistical protocol allows the study of particles deposited on filters while preserving their predominant chemical properties, which makes possible comparisons with those determined by in situ techniques (e.g., Ouf et al., 2016).

Data availability. The data presented here can be provided on request to the contact author.

Supplement. The supplement related to this article is available online at: https://doi.org/10.5194/amt-13-951-2020-supplement.
Author contributions. YC, CP, AF, CI, and CF conceptualized and built the sampling system and defined the methodology; LDN, YC, RI, CI, GL, and CP performed the sample collection; LDN and JAN (SIMS), DD and MV (L2MS), RI, and JAN and CP (Raman) performed the analysis and data reduction; LDN, YC, DD, MV, JAN, $\mathrm{CP}$, and $\mathrm{CF}$ interpreted the results and wrote the original draft with additional contributions from other co-authors: IKO, AF, CI, MZ, and BC. JY, ET, CI, YC, and CF provided funding and access to experimental infrastructure and organized the sampling campaign. All co-authors reviewed and approved the manuscript.

Competing interests. The authors declare that they have no conflict of interest.

Acknowledgements. This work was supported by the French National Research Agency (ANR) through the PIA (Programme d'Investissement d'Avenir) under contract ANR-10-LABX-005 (CaPPA - Chemical and Physical Properties of the Atmosphere), the MERMOSE project sponsored by DGAC (French national funds), and the European Commission Horizon 2020 project PEMs4Nano (H2020 Grant Agreement no. 724145). In addition, the authors thank the Région Hauts-de-France, the Ministère de l'Enseignement Supérieur et de la Recherche (CPER Climibio), and the European Fund for Regional Economic Development for their financial support. Jennifer A. Noble acknowledges the financial support of Horiba Scientific. The collection campaign was financed by GDR Suie (GDR CNRS 3622). The authors acknowledge Nicolas Nuns for his support in acquiring the SIMS data.

Financial support. This research has been supported by the Agence Nationale de la Recherche (grant no. ANR-10-LABX-005), the Région Hauts-de-France (grant CPER CLIMIBIO), the European Union H2020 Research and Innovation programme (grant no. 724145), and the Centre National de la Recherche Scientifique (grant GDR Suie 3622).

Review statement. This paper was edited by Hartmut Herrmann and reviewed by two anonymous referees.

\section{References}

An, Y. Z., Teng, S. P., Pei, Y. Q., Qin, J., Li, X., and Zhao, H.: An experimental study of polycyclic aromatic hydrocarbons and soot emissions from a GDI engine fueled with commercial gasoline, Fuel, 164, 160-171, https://doi.org/10.1016/j.fuel.2015.10.007, 2016.

Atkinson, R. and Arey, J.: Atmospheric chemistry of gasphase polycyclic aromatic hydrocarbons: formation of atmospheric mutagens, Environ. Health Persp., 102, 117-126, https://doi.org/10.1289/ehp.94102s4117, 1994.

Bandowe, B. A. M., Meusel, H., Huang, R., Ho, K., Cao, J., Hoffmann, T., and Wilcke, W.: PM2.5-bound oxygenated PAHs, nitro-PAHs and parent-PAHs from the atmosphere of 
a Chinese megacity: Seasonal variation, sources and cancer risk assessment, Sci. Total Environ., 473-474, 77-87, https://doi.org/10.1016/J.SCITOTENV.2013.11.108, 2014.

Bari, M. A., Baumbach, G., Kuch, B., and Scheffknecht, G.: Particle-phase concentrations of polycyclic aromatic hydrocarbons in ambient air of rural residential areas in southern Germany, Air Qual. Atmos. Hlth., 3, 103-116, https://doi.org/10.1007/s11869-009-0057-8, 2010.

Bentz, J. W. G., Goschnick, J., Schuricht, J., and Ache, H. J.: Depthresolved investigation of the element and compound inventory of aerosol particles from outdoor air, Fresen. J. Anal. Chem., 353, 559-564, https://doi.org/10.1007/BF00321323, 1995.

Bescond, A., Yon, J., Ouf, F. X., Ferry, D., Delhaye, D., Gaffié, D., Coppalle, A., and Rozé, C.: Automated Determination of Aggregate Primary Particle Size Distribution by TEM Image Analysis: Application to Soot, Aerosol Sci. Technol., 48, 831-841, https://doi.org/10.1080/02786826.2014.932896, 2014.

Bescond, A., Yon, J., Ouf, F.-X., Rozé, C., Coppalle, A., Parent, P., Ferry, D., and Laffon, C.: Soot optical properties determined by analyzing extinction spectra in the visible near-UV: Toward an optical speciation according to constituents and structure, J. Aerosol Sci., 101, 118-132, https://doi.org/10.1016/J.JAEROSCI.2016.08.001, 2016.

Brochot, C., Abdolghader, P., Haghighat, F., and Bahloul, A.: Filtration of nanoparticles applied in general ventilation, Sci. Technol. Built En., 25, 114-127, https://doi.org/10.1080/23744731.2018.1500396, 2019.

Butcher, D. J.: Vacuum Ultraviolet Radiation for SinglePhotoionization Mass Spectrometry: A Review, Microchem. J., 62, 354-362, https://doi.org/10.1006/MCHJ.1999.1745, 1999.

Carpentier, Y., Féraud, G., Dartois, E., Brunetto, R., Charon, E., Cao, A.-T., D’Hendecourt, L., Bréchignac, P., Rouzaud, J.-N., and Pino, T.: Nanostructuration of carbonaceous dust as seen through the positions of the 6.2 and $7.7 \mu \mathrm{m}$ AIBs, Astron. Astrophys., 548, A40, https://doi.org/10.1051/0004-6361/201118700, 2012.

Chazallon, B., Ziskind, M., Carpentier, Y., and Focsa, C.: $\mathrm{CO}_{2}$ Capture using semi-clathrates of quaternary ammonium salt: Structure change induced by $\mathrm{CO}_{2}$ and $\mathrm{N}_{2}$ enclathration, J. Phys. Chem. B, 118, 13440-13452, https://doi.org/10.1021/jp507789z, 2014.

Cloutis, E., Szymanski, P., Applin, D., and Goltz, D.: Identification and discrimination of polycyclic aromatic hydrocarbons using Raman spectroscopy, Icarus, 274, 211-230, https://doi.org/10.1016/J.ICARUS.2016.03.023, 2016.

Dachs, J. and Eisenreich, S. J.: Adsorption onto aerosol soot carbon dominates gas-particle partitioning of polycyclic aromatic hydrocarbons, Environ. Sci. Technol., 34, 3690-3697, https://doi.org/10.1021/es991201+, 2000.

Delhaye, D., Ouf, F.-X., Ferry, D., Ortega, I. K., Penanhoat, O., Peillon, S., Salm, F., Vancassel, X., Focsa, C., Irimiea, C., Harivel, N., Perez, B., Quinton, E., Yon, J., and Gaffie, D.: The MERMOSE project: Characterization of particulate matter emissions of a commercial aircraft engine, J. Aerosol Sci., 105, 48-63, https://doi.org/10.1016/J.JAEROSCI.2016.11.018, 2017.

Duca, D., Irimiea, C., Faccinetto, A., Noble, J. A., Vojkovic, M., Carpentier, Y., Ortega, I. K., Pirim, C., and Focsa, C.: On the benefits of using multivariate analysis in mass spectrometric studies of combustion-generated aerosols, Faraday Discuss., 218, 115137, https://doi.org/10.1039/c8fd00238j, 2019.

Elghawi, U. M., Mayouf, A., Tsolakis, A., and Wyszynski, M. L.: Vapour-phase and particulate-bound PAHs profile generated by a (SI/HCCI) engine from a winter grade commercial gasoline fuel, Fuel, 89, 2019-2025, https://doi.org/10.1016/J.FUEL.2010.01.002, 2010.

Ess, M. N., Ferry, D., Kireeva, E. D., Niessner, R., Ouf, F. X., and Ivleva, N. P.: In situ Raman microspectroscopic analysis of soot samples with different organic carbon content: Structural changes during heating, Carbon, 105, 572-585, https://doi.org/10.1016/j.carbon.2016.04.056, 2016.

Ewinger, H.-P., Goschnick, J., and Ache, H. J.: Analysis of organic compounds with SNMS, Fresenius. J. Anal. Chem., 341, 17-19, https://doi.org/10.1007/BF00322099, 1991.

Faccinetto, A., Thomson, K., Ziskind, M., and Focsa, C.: Coupling of desorption and photoionization processes in two-step laser mass spectrometry of polycyclic aromatic hydrocarbons, Appl. Phys. A, 92, 969-974, https://doi.org/10.1007/s00339-008-4605$0,2008$.

Faccinetto, A., Desgroux, P., Ziskind, M., Therssen, E., and Focsa, C.: High-sensitivity detection of polycyclic aromatic hydrocarbons adsorbed onto soot particles using laser desorption/laser ionization/time-of-flight mass spectrometry: An approach to studying the soot inception process in low-pressure flames, Combust. Flame, 158, 227-239, https://doi.org/10.1016/j.combustflame.2010.08.012, 2011.

Faccinetto, A., Focsa, C., Desgroux, P., and Ziskind, M.: Progress toward the Quantitative Analysis of PAHs Adsorbed on Soot by Laser Desorption/Laser Ionization/Time-of-Flight Mass Spectrometry, Environ. Sci. Technol., 49, 10510-10520, https://doi.org/10.1021/acs.est.5b02703, 2015.

Ferge, T., Karg, E., Schröppel, A., Coffee, K. R., Tobias, H. J., Frank, M., Gard, E. E., and Zimmermann, R.: Fast Determination of the Relative Elemental and Organic Carbon Content of Aerosol Samples by On-Line Single-Particle Aerosol Timeof-Flight Mass Spectrometry, Environ. Sci. Technol., 40, 3327 3335, https://doi.org/10.1021/es050799k, 2006.

Ferrari, A. and Robertson, J.: Interpretation of Raman spectra of disordered and amorphous carbon, Phys. Rev. B, 61, 14095-14107, https://doi.org/10.1103/PhysRevB.61.14095, 2000.

Focsa, C., Duca, D., Noble, J. A., Vojkovic, M., Carpentier, Y., Pirim, C., Betrancourt, C., P., Desgroux, Tritscher, T., Spielvogel, J., Rahman, M., Boies, A., Lee, K. F., Bhave, A. N., Legendre, S., Lancry, O., Kreutziger, P., and Rieker, M.: Multitechnique physico-chemical characterization of particles generated by a gasoline engine: towards measuring tailpipe emissions below 23 nm, Atmos. Environ., submitted, 2019.

Haefliger, O. P. and Zenobi, R.: Laser Mass Spectrometric Analysis of Polycyclic Aromatic Hydrocarbons with Wide Wavelength Range Laser Multiphoton Ionization Spectroscopy, Anal. Chem., 70, 2660-2665, https://doi.org/10.1021/ac971264f, 1998.

Hilbig, R.: Narrowband tunable VUV radiation generated by nonresonant sum-and difference-frequency mixing in xenon and krypton, Appl. Optics, 21, 913-917, https://doi.org/10.1364/AO.21.000913, 1982.

Ikhenazene, R., Pirim, C., Noble, J. A., Irimiea, C., Carpentier, Y., Ortega, I. K., Ouf, F. X., Focsa, C., and Chazallon, B.: Ice Nucleation Activities of Carbon-Bearing 
Materials in Deposition Mode: From Graphite to Airplane Soot Surrogates, J. Phys. Chem. C, 124, 489-503 https://doi.org/10.1021/acs.jpcc.9b08715, 2020.

Irimiea, C., Faccinetto, A., Carpentier, Y., Ortega, I. K., Nuns, N., Therssen, E., Desgroux, P., and Focsa, C.: A comprehensive protocol for chemical analysis of flame combustion emissions by secondary ion mass spectrometry, Rapid Commun. Mass Spectrom., 32, 1015-1025, https://doi.org/10.1002/rcm.8133, 2018.

Irimiea, C., Faccinetto, A., Mercier, X., Ortega, I.-K., Nuns, N., Therssen, E., Desgroux, P., and Focsa, C.: Unveiling trends in soot nucleation and growth: When secondary ion mass spectrometry meets statistical analysis, Carbon, 144, 815-830, https://doi.org/10.1016/J.CARBON.2018.12.015, 2019.

Kim, K.-H., Jahan, S. A., Kabir, E., and Brown, R. J. C.: A review of airborne polycyclic aromatic hydrocarbons (PAHs) and their human health effects, Environ. Int., 60, 71-80, https://doi.org/10.1016/J.ENVINT.2013.07.019, 2013.

Le Roy, L., Bardyn, A., Briois, C., Cottin, H., Fray, N., Thirkell, L., and Hilchenbach, M.: COSIMA calibration for the detection and characterization of the cometary solid organic matter, Planet. Space Sci., 105, 1-25, https://doi.org/10.1016/j.pss.2014.08.015, 2015.

Lindsley, W. G.: Filter Pore Size and Aerosol Sample Collection, in NIOSH Manual of Analytical Methods (NMAM), 5th Edition, FP 1-14, available at: https://www.cdc.gov/niosh/docs/ 2014-151/pdfs/chapters/chapter-fp.pdf (last access: 1 July 2019), 2016.

Marhaba, I., Ferry, D., Laffon, C., Regier, T. Z., Ouf, F.-X., and Parent, P.: Aircraft and MiniCAST soot at the nanoscale, Combust. Flame, 204, 278-289, https://doi.org/10.1016/j.combustflame.2019.03.018, 2019.

McLafferty, F. W. and Turecek, F.: Interpretation of mass spectra, University Science Books, Fourth Edition, Sausalito, CA 94965, ISBN 0-935702-25-3, 1993.

Mercier, X., Carrivain, O., Irimiea, C., Faccinetto, A., and Therssen, E.: Dimers of polycyclic aromatic hydrocarbons: the missing pieces in the soot formation process, Phys. Chem. Chem. Phys., 21, 8282-8294, https://doi.org/10.1039/C9CP00394K, 2019.

Mihesan, C., Ziskind, M., Therssen, E., Desgroux, P., and Focsa, C.: IR laser resonant desorption of polycyclic aromatic hydrocarbons, Chem. Phys. Lett., 423, 407-412, https://doi.org/10.1016/J.CPLETT.2006.04.032, 2006.

Mihesan, C., Ziskind, M., Therssen, E., Desgroux, P., and Focsa, C.: Parametric study of polycyclic aromatic hydrocarbon laser desorption, J. Phys. Condens. Matter, 20, 025221, https://doi.org/10.1088/0953-8984/20/02/025221, 2008.

Moldanová, J., Fridell, E., Popovicheva, O., Demirdjian, B., Tishkova, V., Faccinetto, A., and Focsa, C.: Characterisation of particulate matter and gaseous emissions from a large ship diesel engine, Atmos. Environ., 43, 2632-2641, https://doi.org/10.1016/J.ATMOSENV.2009.02.008, 2009.

Moore, R. H., Ziemba, L. D., Dutcher, D., Beyersdorf, A. J., Chan, K., Crumeyrolle, S., Raymond, T. M., Thornhill, K. L., Winstead, E. L., and Anderson, B. E.: Mapping the operation of the miniature combustion aerosol standard (MiniCAST) soot generator, Aerosol Sci. Technol., 48, 467-479, https://doi.org/10.1080/02786826.2014.890694, 2014.

Mueller, L., Jakobi, G., Orasche, J., Karg, E., Sklorz, M., Abbaszade, G., Weggler, B., Jing, L., Schnelle-Kreis, J., and
Zimmermann, R.: Online determination of polycyclic aromatic hydrocarbon formation from a flame soot generator Aerosols and Health, Anal. Bioanal. Chem., 407, 5911-5922, https://doi.org/10.1007/s00216-015-8549-x, 2015.

Munyeza, C. F., Rohwer, E. R., and Forbes, P. B. C.: A review of monitoring of airborne polycyclic aromatic hydrocarbons: An African perspective, Trends Environ. Anal. Chem., 24, e00070, https://doi.org/10.1016/j.teac.2019.e00070, 2019.

Nakagawa, K., Numata, Y., Ishino, H., Tanaka, D., Kobayashi, T., and Tokunaga, E.: Excimer luminescence from nonresonantly excited pyrene and perylene molecules in solution, J. Phys. Chem. A, 117, 11449-11455, https://doi.org/10.1021/jp402330n, 2013.

Nisbet, I. T. and LaGoy, P. K.: Toxic equivalency factors (TEFs) for polycyclic aromatic hydrocarbons (PAHs), Regulatory Toxicology and Pharmacology, Regul. Toxicol. Pharm., 16, 290-300, 1992.

Ouf, F. X., Parent, P., Laffon, C., Marhaba, I., Ferry, D., Marcillaud, B., Antonsson, E., Benkoula, S., Liu, X. J., Nicolas, C., Robert, E., Patanen, M., Barreda, F. A., Sublemontier, O., Coppalle, A., Yon, J., Miserque, F., Mostefaoui, T., Regier, T. Z., Mitchell, J. B. A., and Miron, C.: First in-flight synchrotron X-ray absorption and photoemission study of carbon soot nanoparticles, Sci. Rep., 6, 36495, https://doi.org/10.1038/srep36495, 2016.

Pagels, J., Dutcher, D. D., Stolzenburg, M. R., Mcmurry, P. H., Gälli, M. E., and Gross, D. S.: Fine-particle emissions from solid biofuel combustion studied with single-particle mass spectrometry: Identification of markers for organics, soot, and ash components, J. Geophys. Res.-Atmos., 118, 859-870, https://doi.org/10.1029/2012JD018389, 2013.

Pandey, S. K., Kim, K. H., and Brown, R. J. C.: A review of techniques for the determination of polycyclic aromatic hydrocarbons in air, TRAC-Trend. Anal. Chem., 30, 1716-1739, https://doi.org/10.1016/j.trac.2011.06.017, 2011.

Paolini, V., Guerriero, E., Bacaloni, A., Rotatori, M., Benedetti, P., and Mosca, S.: Simultaneous Sampling of Vapor and Particle-Phase Carcinogenic Polycyclic Aromatic Hydrocarbons on Functionalized Glass Fiber Filters, Aerosol Air Qual. Res., 16, 175-183, https://doi.org/10.4209/aaqr.2015.07.0476, 2017.

Parent, P., Laffon, C., Marhaba, I., Ferry, D., Regier, T. Z., Ortega, I. K., Chazallon, B., Carpentier, Y., and Focsa, C.: Nanoscale characterization of aircraft soot: A high-resolution transmission electron microscopy, Raman spectroscopy, X-ray photoelectron and near-edge X-ray absorption spectroscopy study, Carbon, 101, 86-100, https://doi.org/10.1016/j.carbon.2016.01.040, 2016.

Popovicheva, O. B., Irimiea, C., Carpentier, Y., Ortega, I. K., Kireeva, E. D., Shonija, N. K., Schwarz, J., Vojtíšek-Lom, M., and Focsa, C.: Chemical composition of diesel/biodiesel particulate exhaust by FTIR spectroscopy and mass spectrometry: Impact of fuel and driving cycle, Aerosol Air Qual. Res., 17, 17171734, https://doi.org/10.4209/aaqr.2017.04.0127, 2017.

Ravindra, K., Bencs, L., Wauters, E., De Hoog, J., Deutsch, F., Roekens, E., Bleux, N., Berghmans, P., and Van Grieken, R.: Seasonal and site-specific variation in vapour and aerosol phase PAHs over Flanders (Belgium) and their relation with anthropogenic activities, Atmos. Environ., 40, 771-785, https://doi.org/10.1016/j.atmosenv.2005.10.011, 2006.

Sadezky, A., Muckenhuber, H., Grothe, H., Niessner, R., and Pöschl, U.: Raman microspectroscopy of soot 
and related carbonaceous materials: Spectral analysis and structural information, Carbon, 43, 1731-1742, https://doi.org/10.1016/j.carbon.2005.02.018, 2005.

Stein, S. E. and Fahr, A.: High-temperature stabilities of hydrocarbons, J. Phys. Chem., 89, 3714-3725, https://doi.org/10.1021/j100263a027, 1985.

Sun, P., Blanchard, P., Brice, K. A., and Hites, R. A.: Trends in Polycyclic Aromatic Hydrocarbon Concentrations in the Great Lakes Atmosphere, Environ. Sci. Technol., 40, 6221-6227, https://doi.org/10.1021/es0607279, 2006.

Szulejko, J. E., Kim, K. H., Brown, R. J. C., and Bae, M. S.: Review of progress in solvent-extraction techniques for the determination of polyaromatic hydrocarbons as airborne pollutants, TRAC-Trend. Anal. Chem., 61, 40-48, https://doi.org/10.1016/j.trac.2014.07.001, 2014.

Villanueva, F., Sevilla, G., Lara, S., Martín, P., Salgado, S., Albaladejo, J., and Cabañas, B.: Application of gas chromatography coupled with tandem mass spectrometry for the assessment of PAH levels in non industrial indoor air, Microchem. J., 142, 117 125, https://doi.org/10.1016/J.MICROC.2018.06.021, 2018.

Yon, J., Bescond, A., and Ouf, F. X.: A simple semiempirical model for effective density measurements of fractal aggregates, J. Aerosol Sci., 87, 28-37, https://doi.org/10.1016/j.jaerosci.2015.05.003, 2015.
Yon, J., Ouf, F. X., Hebert, D., Mitchell, J. B., Teuscher, N., Garrec, J. L. Le, Bescond, A., Baumann, W., Ourdani, D., Bizien, T., and Perez, J.: Investigation of soot oxidation by coupling LII, SAXS and scattering measurements, Combust. Flame, 190, 441-453, https://doi.org/10.1016/j.combustflame.2017.12.014, 2018.

Zíková, N., Ondráček, J., and Ždímal, V.: Size-Resolved Penetration Through High-Efficiency Filter Media Typically Used for Aerosol Sampling, Aerosol Sci. Technol., 49, 239-249, https://doi.org/10.1080/02786826.2015.1020997, 2015.

Zimmermann, R., Blumenstock, M., Heger, H. J., Schramm, K.W., and Kettrup, A.: Emission of Nonchlorinated and Chlorinated Aromatics in the Flue Gas of Incineration Plants during and after Transient Disturbances of Combustion Conditions: Delayed Emission Effects, Environ. Sci. Technol., 35, 1019-1030, https://doi.org/10.1021/es0001431, 2001. 